\title{
The relationship between $L p(a)$ and CVD outcomes: a systematic review
}

\author{
Carol A. Forbes ${ }^{1 *}$, Ruben G. W. Quek², Sohan Deshpande ${ }^{1}$, Gill Worthy ${ }^{1}$, Robert Wolff ${ }^{1}$, Lisa Stirk', Jos Kleijnen³ \\ Shravanthi R. Gandra², Stephen Djedjos ${ }^{2}$ and Nathan D. Wong ${ }^{4}$
}

\begin{abstract}
Robust associations between lipoprotein(a) [Lp(a)] and CVD outcomes among general populations have been published in previous studies. However, associations in high risk primary prevention and secondary prevention populations are less well defined. In order to investigate this further, a systematic review was performed including prospective studies, which assessed the relationship between Lp(a) and CVD outcomes using multivariable analyses. Additional information was gathered on $L p(a)$ assays, multivariable modelling and population characteristics. Literature searches from inception up to December 2015 retrieved 2850 records. From these 60 studies were included. Across 39 primary prevention studies in the general population (hazard ratios ranged from 1.16 to 2.97) and seven high risk primary prevention studies (hazard ratios ranged from 1.01 to 3.7), there was evidence of a statistically significant relationship between increased Lp(a) and an increased risk of future CVD. Results in 14 studies of secondary prevention populations were also suggestive of a modest statistically significant relationship (hazard ratios ranged from 0.75 to 3.7$)$.

Therefore current evidence would suggest that increased $L p(a)$ levels are associated with modest increases in the risk of future CVD events in both general and higher risk populations. However, further studies are required to confirm these findings.
\end{abstract}

Keywords: Atherosclerosis, Epidemiology, Lipids, Lipoprotein, Cardiovascular risk

\section{Background}

Cardiovascular disease (CVD) is a leading cause of death and disability [1, 2]. Elevated levels of low-density lipoprotein cholesterol (LDL-C) are a major contributor to atherosclerosis leading to subsequent CVD events. Numerous clinical trials of lipid lowering drugs have found that reducing LDL-C levels substantially reduces the risk of CVD [3-5] suggesting a strong direct relationship between plasma LDL-C levels and CVD outcomes [6, 7]. Many people, however, still have residual CVD risk and suffer from CVD events despite significant LDL-C lowering. In addition to LDL-C, other risk factors are likely to influence residual cardiovascular risk. Among these, lipoprotein(a) [Lp(a)], has been proposed to be independently associated with CVD [8].

\footnotetext{
* Correspondence: carol@systematic-reviews.com

${ }^{1}$ Kleijnen Systematic Reviews Ltd, Unit 6, Escrick Business Park, Riccall Road, Escrick, York YO19 6FD, UK

Full list of author information is available at the end of the article
}

$\mathrm{Lp}(\mathrm{a})$ is an low density lipoprotein (LDL) particle which is attached to the polypeptide, apolipoprotein(a) [apo(a)] [9]. Apo(a) exists in multiple forms or 'kringles', which give rise to different $\mathrm{Lp}(\mathrm{a})$ isoforms. Apo(a) is also believed to be responsible for the anti-fibrinolytic properties of $\mathrm{Lp}(\mathrm{a})$ [9]. Further biomechanisms behind the $\mathrm{Lp}(\mathrm{a})$ and CVD relationship may also involve prothrombotic or proatherosclerotic processes, or a combination of the two [10].

Lp(a) may be measured using a variety of different assays. However, the reliability of many of the assays is questionable, due to their poor abilities at detecting the multiple molecular isoforms of $\mathrm{Lp}(\mathrm{a})$. Consequently, some assays (isoform dependent) that measure $\mathrm{Lp}(\mathrm{a})$ mass cannot distinguish between high and low molecular weight apo(a) isoforms, whilst others (isoform independent) can. However, to our knowledge, at present there appear to be no $\mathrm{Lp}(\mathrm{a})$ assays that are both isoform independent and suited for use clinical laboratories [11]. This problem has led to poor standardisation and comparability 
with respect to the $L p(a)$ values recorded by different assays, which in turn hampers comparisons between trials assessing the relationship between $\mathrm{Lp}(\mathrm{a})$ and CVD [12] Despite this clinical trials have shown that $L p(a)$ is a risk factor in patients on long-term statin treatment [13, 14]. Evidence from the Atherothrombosis Intervention in Metabolic Syndrome with Low HDL/High Triglycerides: Impact on Global Health Outcomes (AIM-HIGH) trial suggests that $\mathrm{Lp}(\mathrm{a})$ is a predictor of CVD events in patients with normal LDL-C levels [15] and recent studies have suggested that elevated $\mathrm{Lp}$ (a) levels like elevated LDL-C, could be associated with premature CVD [8]. Extensive research exists to support an association between $\operatorname{Lp}(\mathrm{a})$ and CVD events with respect to the primary prevention of events in the general population $[16,17]$. This relationship appears to be independent of LDL-C, other lipid levels such as high density lipoprotein (HDL) and the presence of other cardiovascular risk factors [18]. Some evidence from pooled analyses of prospective studies [19-21] suggests a potential association between Lp(a) and risk of CVD among high risk and secondary prevention population. The availability of new data from recently published clinical studies has prompted the need for a more contemporary systematic review. This review assesses the relationship between $L p(a)$ and CVD outcomes, with particular emphasis on high cardiovascular risk populations (high risk primary prevention and secondary prevention). The review also focuses on the best available evidence from studies that used multivariable analysis methods to control for the effect of confounding variables.

\section{Methods}

To reduce the risks of bias and error, this review adhered to a pre-specified protocol and methods recommended by the Cochrane Collaboration [22], and the Centre for Reviews and Dissemination (York, United Kingdom) [23] which are widely regarded as 'gold standard' methodologies.

This review included prospective studies, which assessed the relationship between Lp(a) and CVD outcomes. These studies included randomised controlled trials (RCTs), cohort studies and nested case-control studies. Eligible populations were any adult ( $\geq 18$ years) population regardless of baseline CVD risk, gender, age and ethnicity. Studies had to follow patients for at least 12 months. No restrictions were placed on the CVD outcome or the type of $\mathrm{Lp}(\mathrm{a})$ assay. However, studies were required to use a multivariable analytical approach, which assessed the effect of $\mathrm{Lp}(\mathrm{a})$ on CVD outcomes after adjusting for other confounding factors. At a minimum the analysis had to adjust for baseline age and gender; but this restriction was relaxed for studies in gender and age subgroups or in nested case-control studies where cases and controls were matched on age and gender. Studies were excluded from the review if they fail to clearly report effect sizes based on relevant multivariable analyses.

Extensive literature searches were performed using search strategies developed by an Information Specialist (full strategies are available in Additional file 1). A total of six electronic databases were searched from inception to 31 December 2015 including: MEDLINE, Embase, Medline In-Process \& Daily Update, Cochrane Central Register of Controlled Trials (CENTRAL), Database of Abstracts of Reviews of Effects (DARE) and the Cochrane Database of Systematic Reviews (CDSR). Search strategies were refined and adapted according to the configuration and requirements of each database. The final strategies combined relevant search terms comprising indexed keywords (e.g. Medical Subject Headings, MeSH and EMTREE) and free text terms appearing in the title and/or abstract of database records. Search terms were identified through discussion between the review team, by scanning background literature and 'key articles' already known to the review team, and by browsing database thesauri. Literature searches were not limited by date, language or publication status. Supplementary searches were undertaken in two trials registers (National Institutes of Health [NIH] ClinicalTrials.gov and International Standard Randomised Controlled Trial Number [ISRCTN] Registry) and conference abstracts from four major cardiovascular disease conferences (European Atherosclerosis Society Congress; European Society of Cardiology Congress; American College of Cardiology Annual Scientific Session; and American Heart Association Annual Scientific Sessions, for years 20112015). The reference lists of included studies and systematic reviews were checked for further studies. Identified references were downloaded in Endnote X6 software (Thomson Reuters, New York) for further assessment and handling, and duplicate records were removed.

The study selection process was performed by two reviewers working independently. Data were extracted into a specifically developed spreadsheet in Excel 2010 (Microsoft Corporation, Redmond, Washington). One reviewer extracted the study data and a second reviewer independently reviewed the data against the original paper for completeness and accuracy. Data were extracted on the baseline population (e.g. race and previous CVD events), $\mathrm{Lp}$ (a) assay (e.g. isoform independence), CVD outcomes, statistical analysis methods (details of the type of multivariable model and the variables included) and effect sizes for the relationship between $L p(a)$ and CVD outcomes. The methodological quality (risk of bias) of each study was assessed using the criteria of the Quality in Prognostic Studies (QUIPS) tool [24]. The quality assessments were performed independently by two reviewers. 
Any discrepancies between reviewers during data extraction or quality assessments were resolved through consensus or consultation with a third reviewer.

Meta-analysis was not possible due to heterogeneity in the CVD outcomes, populations and statistical analysis methods. Studies have been summarized in a narrative synthesis accompanied by data tables. It was not possible to plot data on Forest plots due to the absence of necessary data. Effect sizes for Lp(a) are reported as odds ratios (ORs), hazard ratios (HRs) or adjusted Lp(a) levels with accompanying $95 \%$ confidence intervals (CIs) or means/interquartile ranges (IQR). Studies are grouped according to CVD outcome, population and variables included in the multivariable model(s). The term "positive" association refers to an increase in $\mathrm{Lp}(\mathrm{a})$ or higher $\mathrm{Lp}(\mathrm{a})$ levels resulting in an increased risk of CVD outcomes. Similarly a "negative" association refers to an increase in $\mathrm{Lp}(\mathrm{a})$ or higher $\mathrm{Lp}$ (a) levels resulting in a decreased risk of CVD outcomes.

\section{Results}

Literature searches of electronic databases and other sources including hand searching retrieved 3837 titles/ abstracts through December 2015. After de-duplication, a total of 2850 titles/abstracts were screened, and 2189 papers were excluded as having no relevance to the review. Full papers of 312 potentially relevant references were selected for further examination. Of these, $197 \mathrm{pa}-$ pers were excluded after further examination for the following reasons: do not report relevant prognostic factors (20 papers), not relevant outcome (32 papers), not relevant study design (103 papers), and no clearly reported multivariable analysis (42 papers). A total of 60 studies (115 papers) met the criteria for inclusion in the review.

A summary of the identification and selection of studies for inclusion in this review is presented in Fig. 1, in accordance with the PRISMA [25].

The 60 studies included ten RCTs, 37 prospective cohort studies and 13 nested case control studies. A summary of the studies is reported in Table 1 and further information about individual studies is available in an Additional file 2: Table S1.

Overall, across all 60 studies, the level of bias was assessed as moderate. However 13 studies were assessed as having a high risk of bias and five studies as a low risk of bias; 11 studies failed to report sufficient detail so as to allow a full assessment of the risk of bias. Those studies that were of high risk of bias often had methodological issues within the QUIPS domains 2 and 3 concerning study attrition and prognostic factor [i.e. $\mathrm{Lp}(\mathrm{a})$ ] measurement respectively. Reporting across studies was not always sufficiently detailed to allow a judgement to be made and 16 studies were reported as not having enough information to make a judgement for at least one of the six QUIPS criteria. Further details of the risk of bias assessments for the individual studies are available in a Additional file 3: Table S2.

\section{Primary prevention studies}

The majority of the identified studies (39 studies) were carried out in participants from the general population, i.e. did not select patients based on their baseline history or risk of CVD events. Further details of the characteristics of the studies in the general population are reported in Table 2. These included four RCTs, 25 prospective cohort studies and 10 nested case-control studies. Thirteen studies [26-38] were conducted in males and two in females $[39,40]$. Specific ethnic groups were used in some studies including populations from South Korea [41, 42], Native American Indians (from the USA) [43], Japan [44, 45] and Taiwan [46]. Follow-up in the studies tended to be longer than in the high risk and secondary prevention populations, with 20 out of 39 studies (52.3\%) having a follow-up of 5 to $\leq 10$ years and 11 out of 39 studies; $28.2 \%$ ) following participants for over $10 \mathrm{yrs}$. The longest follow-up period was 20 years in the ARIC study [47]. The risk of bias across the 39 studies was assessed as low in two studies (5.4\%); moderate in 22 studies $(84.0 \%)$, high in seven studies (17.9\%) and there was insufficient information to make an assessment in eight $(20.5 \%)$ studies. Only $12(30.8 \%)$ studies used assays that were reported as isoform independent and five (12.8\%) used assays on fresh plasma samples. The majority of studies used a Cox proportional hazards model (20 studies; $51.3 \%$ ); other models included logistic regression (11 studies; $28.2 \%$ ), conditional logistic regression (seven studies; $17.9 \%$ ), and both conditional and unconditional logistic regression (one study; $2.6 \%$ ).

Half of the studies included LDL-C (19 studies; $48.7 \%$ ) as a covariate in the multivariable model and all but four of these studies (Justification for the Use of Statins in Primary Prevention: An Intervention Trial Evaluating Rosuvastatin trial [JUPITER] [14], PRospective du l'Infarctus MyocardE; prospective epidemiological study of myocardial infarction [PRIME] [34], Invecchiare in Chianti [InCHIANTI] Study [48] and Atherosclerosis Risk in Communities [ARIC] [49]) reported significant positive associations between Lp(a) and CVD. The JUPITER study [14] and PRIME [34] each reported two negative associations between $\mathrm{Lp}(\mathrm{a})$ and CVD events, but in both cases these were for subgroup analyses and the results were not statistically significant. In the case of the JUPITER study [14] the authors concluded that among white participants treated with potent statin therapy, Lp(a) concentrations (at baseline and on-statin) were a significant determinant of residual risk with respect to CVD events; and in the PRIME study [34] that increased baseline $\mathrm{Lp}(\mathrm{a})$ levels (considered as the $\mathrm{Lp}(\mathrm{a})$ 


\section{RECORDS RETRIEVED AND SCREENED}

(TITLE/ABSTRACT SCREENING)

3837records prior to de-duplication

MEDLINE: 1716

MEDLINE IN-PROCESS \& DAILY UPDATE: 43

EMBASE: 1057

CENTRAL: 404

Other resources: 528

Hand searching/reference checking: 89

Duplicates Removed: 987

TOTAL: 2850 records after de-duplication

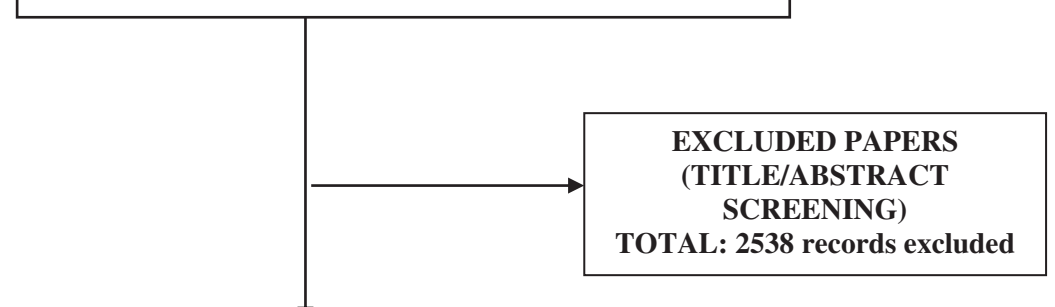

FULL PAPERS ASSESSED

(FULL PAPER SCREENING)

TOTAL: 312 papers

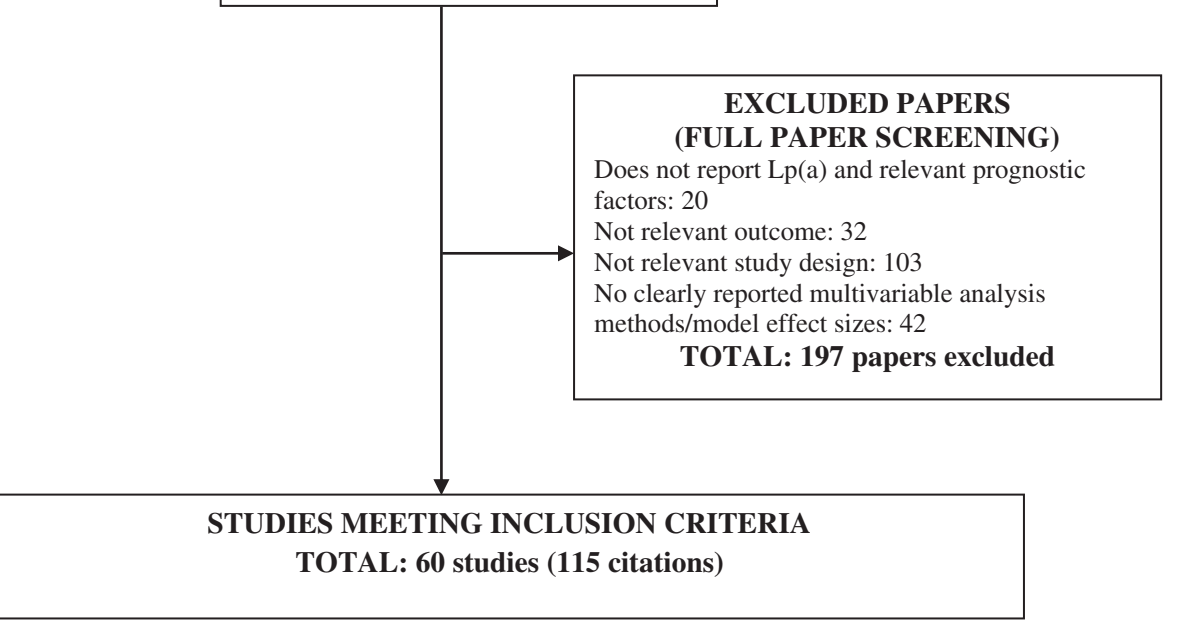

Fig. 1 Preferred Reporting Items for Systematic Reviews and Meta-Analyses (PRISMA) flow diagram for the selection of studies

cholesterol content) were significantly associated with the risk for MI and angina pectoris, especially in men with high LDL-C. In the ARIC study [49] a significant negative association with $\operatorname{Lp}(\mathrm{a})$ mass was reported for a subgroup analysis of ischemic strokes in white females, when comparing $>6.6$ to $\leq 14.6 \mathrm{mg} / \mathrm{dL} \mathrm{Lp}$ (a) [Quintile 4] versus 0.1 to $\leq 1.6 / \mathrm{dL} \mathrm{Lp}(\mathrm{a})$ [Quintile 1]. However, this result was based on a small number of events suggesting that it may not be robust and was in contrast to the overall trend of the other primary and subgroup analyses, which suggested that overall a positive association existed between Lp(a) mass and CVD events. Overall, the authors concluded that Lp(a) mass was positively associated with CVD events, but that it appeared stronger in blacks compared to whites. The InCHIANTI study [48] did not report any statistically significant associations after following patients longitudinally for six years, but did find evidence of a link between prevalent peripheral arterial disease (PAD) and Lp(a). The authors concluded that $\mathrm{Lp}(\mathrm{a})$ concentration was an independent predictor of PAD in the cross-sectional evaluation, but that further larger, longer duration, prospective studies are needed to establish a longitudinal association.

Among the remaining half of the studies which did not include LDL-C as a covariate in their multivariable models, a further four studies (Physician's Health Study [PHS] [33, 50], Italian Longitudinal Study on Aging [ILSA] [51] Uppsala Longitudinal Study of Adult Men 
Table 1 Summary of characteristics across included studies (60 studies)

\begin{tabular}{|c|c|c|c|c|c|c|c|c|c|c|c|}
\hline \multirow[t]{2}{*}{$\begin{array}{l}\text { Study } \\
\text { population }\end{array}$} & \multicolumn{3}{|c|}{$\begin{array}{l}\text { Study design } \\
\text { (no. stds.) }\end{array}$} & \multicolumn{2}{|c|}{$\begin{array}{l}\text { Age } \\
\text { (no. stds.) }\end{array}$} & \multicolumn{3}{|c|}{$\begin{array}{l}\text { Gender } \\
\text { (no. stds.) }\end{array}$} & \multicolumn{3}{|c|}{$\begin{array}{l}\text { Ethnicity } \\
\text { (no. stds.) }\end{array}$} \\
\hline & RCTs & $\begin{array}{l}\text { Prospective } \\
\text { cohort }\end{array}$ & $\begin{array}{l}\text { Nested } \\
\text { case } \\
\text { control }\end{array}$ & $\begin{array}{l}< \\
65 \\
\text { years }\end{array}$ & $\begin{array}{l}\geq \\
65 \\
\text { years }\end{array}$ & $\begin{array}{l}\text { Males } \\
\text { only }\end{array}$ & $\begin{array}{l}\text { Females } \\
\text { only }\end{array}$ & $\begin{array}{l}\text { Males } \\
\text { and } \\
\text { females }\end{array}$ & $\begin{array}{l}\text { White } \\
\text { only }\end{array}$ & $\begin{array}{l}\text { Non- } \\
\text { White } \\
\text { only }\end{array}$ & $\begin{array}{l}\text { Mixed } \\
\text { or not } \\
\text { reported/ } \\
\text { unclear }\end{array}$ \\
\hline $\begin{array}{l}\text { Primary } \\
\text { prevention } \\
\text { General } \\
\text { population } \\
\text { (39 studies) }\end{array}$ & 4 & 25 & 10 & 36 & 3 & 13 & 2 & 24 & 15 & 5 & 19 \\
\hline $\begin{array}{l}\text { Primary } \\
\text { prevention } \\
\text { High risk } \\
\text { population } \\
\text { (7 studies) }\end{array}$ & 1 & 6 & 0 & 7 & 0 & 1 & 0 & 6 & 1 & 2 & 4 \\
\hline $\begin{array}{l}\text { Secondary } \\
\text { prevention } \\
\text { Previous } \\
\text { CVD events } \\
\text { (14 studies) }\end{array}$ & 5 & 8 & 1 & 14 & 0 & 1 & 1 & 11 & 1 & 4 & 9 \\
\hline $\begin{array}{l}\text { TOTAL } \\
\text { (out of } 60 \\
\text { studies) }\end{array}$ & 10 & 39 & 11 & 57 & 3 & 15 & 3 & 41 & 17 & 11 & 32 \\
\hline
\end{tabular}


Table 1 Summary of characteristics across included studies (60 studies) (Continued)

\begin{tabular}{|c|c|c|c|c|c|c|c|c|c|c|c|}
\hline \multirow[t]{2}{*}{$\begin{array}{l}\text { Study } \\
\text { population }\end{array}$} & \multicolumn{4}{|c|}{$\begin{array}{l}\text { Risk of bias } \\
\text { (no. stds.) }\end{array}$} & \multicolumn{7}{|l|}{$\begin{array}{l}\text { Model type } \\
\text { (no. stds.) }\end{array}$} \\
\hline & High & Moderate & Low & $\begin{array}{l}\text { Not } \\
\text { enough } \\
\text { information }\end{array}$ & $\begin{array}{l}\text { Cox } \\
\text { proportional } \\
\text { hazards }\end{array}$ & $\begin{array}{l}\text { Logistic } \\
\text { regression }\end{array}$ & $\begin{array}{l}\text { Conditional } \\
\text { \&unconditional } \\
\text { logistic }\end{array}$ & $\begin{array}{l}\text { Discriminant } \\
\text { analysis }\end{array}$ & Other & Conditional logistic regression & Includes LDL-C as model variable \\
\hline $\begin{array}{l}\text { Primary } \\
\text { prevention } \\
\text { General } \\
\text { population } \\
\text { (39 studies) }\end{array}$ & 7 & 22 & 2 & 8 & 20 & 11 & 1 & 0 & 0 & 7 & 18 \\
\hline $\begin{array}{l}\text { Primary } \\
\text { prevention } \\
\text { High risk } \\
\text { population } \\
\text { (7 studies) }\end{array}$ & 4 & 1 & 1 & 1 & 4 & 1 & 0 & 0 & 1 & 0 & 1 \\
\hline $\begin{array}{l}\text { Secondary } \\
\text { prevention } \\
\text { Previous } \\
\text { CVD events } \\
\text { (14 studies) }\end{array}$ & 2 & 7 & 2 & 3 & 11 & 3 & 0 & 0 & 1 & 0 & 2 \\
\hline $\begin{array}{l}\text { TOTAL } \\
\text { (out of } 60 \\
\text { studies) }\end{array}$ & 13 & 30 & 5 & 11 & 35 & 15 & 1 & 0 & 2 & 7 & 21 \\
\hline
\end{tabular}

no. number; std. studies

aisk of bias according to Quality In Prognosis Studies (QUIPS) risk of bias assessment tool [24] 
Table 2 Summary of primary prevention studies in the general population (39 studies)

\begin{tabular}{|c|c|c|}
\hline Item & Category & $\begin{array}{l}\text { Number of } \\
\text { studies (\%) }\end{array}$ \\
\hline \multirow[t]{3}{*}{ Study design } & $\mathrm{RCT}$ & 4/39 (10.3\%) \\
\hline & Prospective cohort study & 25/39 (64.1\%) \\
\hline & Nested case-control study & 10/39 (25.6 \%) \\
\hline \multirow[t]{5}{*}{ Follow-up } & $1 \mathrm{yr}$ to $<2 \mathrm{yrs}$ & $1 / 39(2.6 \%)$ \\
\hline & 2 yrs to $<5$ yrs & 4/39 (10.3\%) \\
\hline & 5 yrs to $<10$ yrs & 20/39 (52.3\%) \\
\hline & 10 yrst & 11/39 (28.2\%) \\
\hline & Not reported or unclear & 3/39 (7.7 \%) \\
\hline \multirow[t]{3}{*}{ Gender } & Males only & 13/39 (33.3\%) \\
\hline & Females only & 2/39 (5.1\%) \\
\hline & Mixed males and females & 24/39 (61.5\%) \\
\hline \multirow[t]{2}{*}{ Age } & $<65$ yrs & 36/39 (92.3\%) \\
\hline & Elderly $\geq 65$ yrs & 3/39 (7.7 \%) \\
\hline \multirow[t]{7}{*}{ Ethnicity } & Mixed & 3/39 (7.7 \%) \\
\hline & Korean & 2/39 (5.1\%) \\
\hline & Taiwanese & $1 / 39(2.6 \%)$ \\
\hline & Japanese & $1 / 39(2.6 \%)$ \\
\hline & Native American Indian & $1 / 39(2.6 \%)$ \\
\hline & White (majority populations) & 15/39 (38.5 \%) \\
\hline & Not reported/unclear & 16/39 (41.0\%) \\
\hline \multirow[t]{5}{*}{ Model method ${ }^{a}$} & Cox proportional hazards & 20/39 (51.3\%) \\
\hline & Logistic regression & $11 / 39(28.2 \%)$ \\
\hline & $\begin{array}{l}\text { Conditional and unconditional } \\
\text { logistic regression }\end{array}$ & $1 / 39(2.6 \%)$ \\
\hline & Conditional logistic regression & 7/39 (17.9\%) \\
\hline & Discriminant analysis & 0/39 (0 \%) \\
\hline \multirow[t]{2}{*}{ Model variables } & Includes LDL-C as model variable & 19/39 (48.7 \%) \\
\hline & $\begin{array}{l}\text { Does not include LDL-C or unclear/ } \\
\text { not reported }\end{array}$ & 19/39 (48.7\%) \\
\hline \multirow[t]{4}{*}{ Lp(a) assay } & Isoform dependent & $1 / 39(2.6 \%)$ \\
\hline & Isoform independent & 12/39 (30.8\%) \\
\hline & $\begin{array}{l}\text { Isoform independent and } \\
\text { dependent }\end{array}$ & $1 / 39(2.6 \%)$ \\
\hline & Isoform independence NR or unclear & 25/39 (61.4\%) \\
\hline \multirow[t]{4}{*}{ Sample type } & Fresh plasma samples & $5 / 39(12.8 \%)$ \\
\hline & Frozen plasma samples & 25/39 (64.1\%) \\
\hline & Mixture of frozen and fresh samples & 2/39 (5.1\%) \\
\hline & Not reported or unclear & 7/39 (17.9 \%) \\
\hline \multirow[t]{4}{*}{ Risk of bias } & Low & 2/39 (5.1\%) \\
\hline & Moderate & $22 / 39(56.4 \%)$ \\
\hline & High & 7/39 (17.9 \%) \\
\hline & Not enough information & $8 / 39(20.5 \%)$ \\
\hline
\end{tabular}

LDL-C low density lipoprotein; Lp(a) lipoprotein (a); NR not reported; $R C T$ randomised controlled trial; yrs years

${ }^{\text {a }}$ Note some studies report multiple types of models
[USLM] [26] and Women's Health Initiative Observational Study/Hormones and Biomarkers Predicting Stroke Studies[WHI-OS/HaBPS] [39]) reported some negative associations between $\mathrm{Lp}(\mathrm{a})$ mass and CVD events. Negative statistically insignificant associations in the USLM study [26] were reported for the relationship between $\mathrm{Lp}$ (a) mass and intracerebral haemorrhage, but the authors concluded that high serum Lp(a) level independently predicted fatal and non-fatal stroke/transient ischemic attack (TIA) in a population of middle-aged men followed for 32 years. In the ILSA study [51] no overall statistically significant association was found between high Lp(a) levels and the risk of all-cause mortality, cumulative fatal-nonfatal stroke, and cumulative fatal-nonfatal coronary artery disease (CAD) events. However, the authors reported that high $\mathrm{Lp}(\mathrm{a})$ levels were an independent and significant predictor of non-fatal CAD events after 6.3 years in an elderly (65 to 84 years) population [51]. No association was also reported for $\mathrm{Lp}(\mathrm{a})$ concentration and ischemic stroke in the WHI-OS/HaBPS [39] study, where the authors concluded that they found no significant relationship between $\mathrm{Lp}(\mathrm{a})$ and ischemic stroke in postmenopausal women. However, the methods used to measure Lp(a) were not well described in this study and so their reliability was unclear. The PHS study [33] also found no evidence that $\mathrm{Lp}(\mathrm{a})$ levels were a significant predictor of PAD in men.

\section{High risk primary prevention studies}

Seven studies assessed the relationship between $\mathrm{Lp}(\mathrm{a})$ and CVD outcomes in populations at high risk of CVD events, but who had not as yet experienced a CVD event (Agewall 2002; [52] Choices for Healthy Outcomes in Caring for End Stage Renal Disease study [CHOICE]; [53] Cleveland Clinic Hemodialysis Cohort; [54] Diamant Alpin Collaborative Dialysis Cohort; [55] Japan Diabetes Complications Study [JDCS]; [56] Koda 1999; [57] and Zimmermann 1999 [58]). Follow-up in the studies ranged from 2 years $[14,55,57]$ to 7.8 years [56] and the sample size ranged from 118 [59] to 1494 [60] participants. These studies included patients with hypertension [52, 55], dialysis patients $[55,57,58,61,62]$ and patients with diabetes [55-57,63]. Five studies were in mixed gender populations [54-58, 61, 64], with one study in older (aged 56 to 77 yrs) males [52]. Two of the studies were in Japanese populations [56, 57]. A summary of the characteristics and effect sizes for these studies is shown in Table 3.

The overall quality of the six prospective cohort studies $[53-55,57,58,64]$ and one RCT [65] was mixed, with the risk of bias assessed as high in four studies [52, 55-57], moderate in two studies [54,61] and low in one study [58].

CVD outcomes assessed in the studies were individual and composite outcomes including coronary heart disease 
Table 3 Summary of primary prevention studies in high risk populations (7 studies)

\begin{tabular}{|c|c|}
\hline Study Details & Analysis Methods \\
\hline $\begin{array}{l}\text { Agewall } 2002[52] \text { ( } n=118) \\
\text { Study design: Prospective cohort study } \\
\text { Follow-up: } 3.0 \pm 0.6 \text { yrs } \\
\text { Population description: Males } 56 \text { to } 77 \text { yrs with } \\
\text { treated hypertension } \\
\text { Overall risk of biass: High risk } \\
\text { Funding: NR }\end{array}$ & $\begin{array}{l}\text { Model: Cox proportional hazards } \\
\text { Variables: Age and other variables; LDL-C not inclu } \\
\text { CVD Outcomes: Non-fatal Ml or CD } \\
\text { Lp (a) assay: Isoform independence - NR; NR if fresh } \\
\text { frozen samples }\end{array}$ \\
\hline $\begin{array}{l}\text { CHOICE [53] ( } n=833 \text { ) } \\
\text { Study design: Prospective cohort study } \\
\text { Follow-up: Median } 27.4 \text { mths } \\
\text { Population description: Mixed gender adults } \\
17 \text { yrs + on dialysis } \\
\text { Overall risk of bias }{ }^{\text {a }} \text { : Moderate risk } \\
\text { Funding: Public/government }\end{array}$ & $\begin{array}{l}\text { Model: Cox proportional hazards } \\
\text { Variables: Age, gender and other variables; LDL-C } \\
\text { not included } \\
\text { CVD Outcomes: ASCVD } \\
\text { Lp(a) assay: Isoform independent; } \\
\text { frozen samples }\end{array}$ \\
\hline
\end{tabular}

Cleveland Clinic Hemodialysis Cohort [54] $(n=129)$ Study design: Prospective cohort study

Follow-up: 4 yrs

Population description: Mixed gender adults $\geq 18 \mathrm{yrs}$ on haemodialysis

Risk of bias assessment overall: Moderate risk

Funding: Public/government

Diamant Alpin Collaborative Dialysis Cohort [55] $(n=279)$ Study design: Prospective cohort study

Follow-up:2 yrs

Population description:

Mixed gender adults 22 to 92 yrs with and without type 2 diabetes

Risk of bias assessment overall: : High risk

Funding: Pharma

JDCS [56] $(n=1304)$

Study design: RCT

Follow-up: Median 7.8 yrs

Population description: Mixed gender Japanese adults

40 to 70 yrs with Type 2 diabetes

Risk of bias assessment overall": High risk

Funding: Public/government
Model: Multiple regression (OR) and Cox proportional hazards (HR)

Variables: Gender and other variables; includes LDL-C CVD Outcomes: Atherosclerotic events including stroke and $\mathrm{Ml}$

Lp(a) assay: Isoform independence -NR/unclear; frozen samples

Model: Cox proportional hazards regression Variables: Age, gender and other variables; LDL-C not included

CVD Outcomes: CVD events (Ml, de novo angina pectoris or coronary

revascularization, ischemic stroke, or PAD) and CV death (due to cardiac

arrhythmia, Ml, or HF)

Lp(a) assay: NR/unclear; Immunoturbidimetric assay; Isoform dependence -

NR/unclear; NR if fresh or frozen samples

Model: Cox proportional hazards

Variables: Age, gender and other variables; LDL-C not included

CVD Outcomes: Stroke (ischemic, hemorrhagic

or TIA), CHD

$L p(a)$ assay: Isoform independence -NR/unclear;

frozen samples
Summary of findings

Lp(a) comparison type: Continuous

Two effects sizes reported, each using a different model for the relationship between log per $\mathrm{Lp}(\mathrm{a})$ increase and non-fatal $\mathrm{Ml}$ or $\mathrm{CD}$ : HR 2.84, 95 \% Cl: 1.06 to 7.63 (adjusted for age, BP, smoking,

cholesterol, diabetes)

HR 2.97, $95 \%$ Cl: 1.03 to 8.37 (adjusted for CD at entry)

Both were statistically significant showing that $L p(a)$ is a significant and

independent predictor for major coronary events

Lp(a) comparison type: Categorical

Ten effect sizes reported from five models of two categorical comparisons.

Nine out of ten showed a statistically significant, positive association

(same direction) for $L p(a)$ with respect to ASCVD.

Maximum effect size reported was for $L p(a) \geq 206 \mathrm{nmol} / \mathrm{L}$ (ref) vs.

L p (a) $<206 \mathrm{nmol} / \mathrm{L}$ (HR 1.89, $95 \% \mathrm{Cl}: 1.3$ to 2.75 ).

One effect size was NS: Lp(a) $\geq 52.5 \mathrm{nmol} / \mathrm{L}$ (ref) Vs. $L p(a)<52.5 \mathrm{nmol} / \mathrm{L}$

(HR 1.25, $95 \%$ Cl: 0.99 to 1.58 )

The authors concluded that ASCVD was significantly and independently associated with high $L p(a)(>123 \mathrm{nmol} / \mathrm{L})$ and low molecular weight (LMW) apo(a) isoforms, though a stronger relationship was found for ASCVD and low molecular weight isoform size. This is in ESRD patients and there was a high transplantation rate $(17.3 \%)$ which may have biased the Lp(a) results Lp(a) comparison type: Continuous

Two effect sizes reported for $L p(a)$ with respect to atherosclerotic events: OR $1.02,95 \%$ Cl: 1.01 to 1.04 (multiple regression)

HR $1.603,95 \%$ Cl: 1.08 to 2.38 (Cox proportional)

A $1-\mathrm{mg} / \mathrm{dL}$ or $10-\mathrm{mg} / \mathrm{dll}$ increment in baseline $\mathrm{Lp}(\mathrm{a})$ concentration was associated with a 1.02 or 1.26 increase, respectively, in the relative risk of sustaining an event $(p=0.001)$

Both results suggested that baseline $L p(a)$ is a significant and independent risk factor for clinical events

Lp(a) comparison type: Categorical

One effect size reported which showed a statistically significant positive association (same direction) for $L p(a)>300 \mathrm{mg} / \mathrm{L}$ vs $\leq 300$ with CVD events and CV deaths: HR 1.67, 95 \% Cl: 1.04 to 2.63

This result suggested that $L p(a)$ is an independent and significant predictor of $\mathrm{CV}$ events.

Lp(a) comparison type: Continuous

One effect size reported which showed a statistically significant positive association (same direction) of $L p(a)$ (per $1 \mu \mathrm{mol} / \mathrm{l}$ increase) with an increased risk of stroke (ischemic, hemorrhagic or TIA): HR 1.16, $95 \%$ Cl: 1.03 to 1.31

Suggests that increasing $L p(a)$ is and independent and significant risk factor for stroke 
Table 3 Summary of primary prevention studies in high risk populations (7 studies) (Continued)

Koda 1999 [57] $(n=390)$

Study design: Prospective cohort study

Follow-up:2.3 yrs

Population description:

Mixed gender Japanese adults $\geq 18$ yrs with or

without type 2 diabetes receiving haemodialysis

Risk of bias assessment overall: High risk

Funding: NR/unclear

Zimmermann 1999 [58] $(n=440)$

Study design: Prospective cohort study

Follow-up: 12 and 24mths

Population description: White mixed gender adults

20 to 88 yrs on chronic haemodialysis

Risk of bias assessment overall: : Low risk

Funding: Public/government
Model: Multiple logistic regression model

Variables: Age, gender, albumin, Lp(a), diabetic state: LDL-C not included

CVD Outcomes: Death and CV death

p(a) assay: NR/unclear; Immunoturbidimetric assay;

soform dependence

NR/unclear; NR if fresh or frozen samples

Model: Cox proportional hazards

Variables: Age, gender and other variables; LDL-C not included Lp(a) was significantly associated with risk of all-cause and cardiovascular CVD Outcomes: All deaths, stroke, HF, MI

Lp(a) assay: Isoform independence - NR; fresh samples
Lp(a) comparison type: Categorical

One effect size reported for $L p(a)$ showed a statistically significant positive association (same direction) with respect to CV death, comparing High

Lp(a) $[\geq 30 \mathrm{mg} / \mathrm{dL}]$ vs Low Lp(a) [<30 mg/dL]: OR 3.93, $95 \%$ Cl: NR. This association was statistically significant

One effect size reported for $L p(a)$ with respect to overall death, comparing High Lp(a) [ $\geq 30$ mg/dL] vs Low Lp(a) [<30 mg/dL]: OR 1.9795 \% Cl: NR. This association was not statistically significant.

suggests that high $L p(a)[\geq 30 \mathrm{mg} / \mathrm{dL}$ is an independent and significant risk factor for atherosclerotic CV death, but not overall death.

p(a) comparison type: Categorical the multivariaviate Cox regression analy

This study is in haemodialysis patients, in such patients $L p(a)$ reacts as an acute phase protein in combination with other factors such as fibrinogen $\mathrm{HDL}-\mathrm{C}$ and Apo A-I, changing the atherogenic risk profile. When Lp(a) is added to the multivariable model with these other variables $L p(a)$ no

longer remains significant as an independent factor.

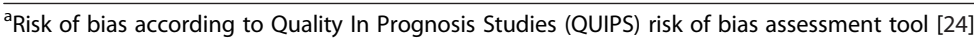

ASCVD atherosclerotic cardiovascular disease; CD coronary death; CHD coronary heart disease; CHOICE Choices for Healthy Outcomes in Caring for ESRD; CI confidence interval; CVD cardiovascular events; ESRD end stage renal disease; HF heart failure; HR hazard ratio; JDCS Japan Diabetes Complications Study; LDL-C low density lipoprotein cholesterol; OR odds ratio; MI myocardial infarction; mth months; NR not reported; NS not statistically significant; RCT randomised controlled trial; TIA transient ischemic attack; yrs years 
(CHD) [56], non-fatal myocardial infarction (MI) [52, 55], cardiovascular death [52, 55, 57], atherosclerotic events $[53,54]$, non-haemorrhagic stroke $[54,65]$, heart failure (HF) [58], TIA [56] and all deaths [57, 58]. Six studies used Cox proportional hazards models [54-56, 58, 61, 64], with one study reporting results from stepwise multiple logistic and Cox regression analyses [54]. and one reporting a multiple logistic regression model [57]. Age was considered as a variable in all but one study [54], and similarly gender was considered in all but one study [52]. All of the studies included additional variables. These varied in type and number across the studies and studies reported different results for models adjusted with different groups of variables. However, only one study included LDL-C in their model [54]. This study (Cleveland Clinic Hemodialysis Cohort) [54] found that baseline Lp(a) concentration was a significant independent risk factor $(p=0.001)$ for clinical events attributed to atherosclerotic cardiovascular disease in patients receiving chronic haemodialysis treatment of end-stage renal disease. The only study to report the use of an isoform independent $\mathrm{Lp}(\mathrm{a})$ assay (CHOICE [53]) similarly reported that high $\mathrm{Lp}(\mathrm{a})$ levels $(\geq 52.5 \mathrm{nmol} / \mathrm{L})$ predicted a $30 \%$ to $40 \%$ increased risk of elevated atherosclerotic cardiovascular disease (ASCVD) in dialysis patients, but that the association of ASCVD with low molecular weight LMW isoforms (increased risk of $60 \%$ to $90 \%$ ) was stronger than the association with high $\mathrm{Lp}(\mathrm{a})$ concentration.

In half of the studies $\mathrm{Lp}(\mathrm{a})$ levels were included as a continuous variable and the other half of the studies used categorical data. Of the eight studies, only one failed to find a significant relationship between $\mathrm{Lp}(\mathrm{a})$ and CVD outcomes (Zimmermann 1999 [58]). This study in haemodialysis patients reported that serum Lp(a) concentration was a significant predictor in univariate analyses, but that significance was lost when $\mathrm{Lp}$ (a) concentration was included in multivariable models for death and cardiovascular death [58]. This study was carried out in stable haemodialysis patients measuring outcomes at two years and the authors suggested that $\mathrm{Lp}(\mathrm{a})$ was only involved in an acute phase reaction. All of the remaining studies showed a positive association, i.e. that increased $\mathrm{Lp}(\mathrm{a})$ levels increased the risk of CVD events; hazard ratios (HRs) ranged from 1.16 to 2.97 .

\section{Secondary prevention studies}

Fourteen studies assessed the relationship between $\mathrm{Lp}(\mathrm{a})$ and CVD outcomes in patients with previous CVD events (Scandinavian Simvastatin Survival Study [4S Study]; [66] Atherothrombosis Intervention in Metabolic Syndrome With Low HDL/High Triglycerides: Impact on Global Health Outcome trial [AIM-HIGH]; [67] Ezhov 2014;
[68] Global Evaluation of New Events and Restenosis After Stent Implantation [GENERATION] study; [69] Heart and Estrogen/progestin Replacement Study [HERS]; [70] Ikenaga 2011; [71] Park 2015; [72] Konishi 2013; [45] Kwon 2015; [73] Long-Term Intervention with Pravastatin in Ischaemic Disease [LIPID] study; [13] RapamycinEluting Stent Evaluated At Rotterdam Cardiology Hospital study [RESEARCH]; [74] Rosengren 1990; [75] Treating to New Targets [TNT] study; [76] and Wehinger 1999 [77]). Follow-up in the studies ranged from 1 year [77] to $8.5 \pm 3.5$ years [68] and the sample size ranged from 115 [75] to 4444 [66] participants. These studies included patients with previous MI/CHD disease [63], [66, 70, 75, 76] CAD; [73] stent placement after symptomatic CAD $[63,72,77]$, patients undergoing percutaneous coronary intervention (PCI) $[45,71,78]$, history of CVD [13, 60, 67], patients after successful coronary artery bypass graft (CABG) [68] and patients hospitalised for stable angina, non-ST elevation acute coronary syndromes (NSTACS) or ST-segment elevation myocardial infarction (STEMI) $[63,69]$. The majority of studies were in mixed gender populations with the exception of two studies in men $[69,75]$ and one in elderly postmenopausal women [70]. Two of the studies were in Japanese populations $[45,71]$ and two in Korean populations [72, 73]. A summary of the characteristics and effect sizes for these studies is shown in Table 4.

The overall quality of the eight prospective cohort studies $[45,68,69,71-74,77]$, one nested case-control study [75] and five RCTs [13, 66, 67, 70, 76] was mixed, with the risk of bias assessed as moderate in seven studies $[13,66,72-75,77]$ low in two studies $[67,68]$ and high in two studies $[45,76]$. There was insufficient information to make a proper assessment in the remaining three studies due to poor reporting [69-71].

CVD outcomes assessed in the studies were individual and combined outcomes including the following: CHD [70], non-fatal MI [13, 68-70, 75], cardiovascular death $[13,75,76],[69,70,79]$ stroke [67], MACE [66, 71-74], hospitalisation for angina [68, 69], MI [70, 72, 76] TIA [67] angiographic restenosis [72, 77] and all deaths [45, 66]. Twelve studies used Cox proportional hazards models [13, $67-74,76,77,80]$, and two studies used logistic regression $[66,75]$. All of the studies considered age and gender in their analyses. The other variables used in the analyses differed in type and number across the studies and on occasions the studies reported results for models adjusted for different groups of variables. Only two studies included LDL-C level in their model (HERS [70] and Park 2015 [70, 72]) and binary restenosis and 3 yr adverse clinical outcomes in an Asian population $(\mathrm{Lp}(\mathrm{a})>$ $50 \mathrm{mg} / \mathrm{dL}$ (versus $\mathrm{Lp}(\mathrm{a}) \leq 50 \mathrm{mg} / \mathrm{dL}$ [reference]: OR 2.88, $95 \%$ CI: 1.37 to 6.07) [72]. In addition, one further study (Kwon 2015 [73]) included the presence of 
Table 4 Summary of studies in secondary prevention (14 studies)

\begin{tabular}{|c|c|c|}
\hline Study Details & Analysis Methods & Summary of findings \\
\hline $\begin{array}{l}\text { 4S Study [66] ( } n=4444) \\
\text { Study design: RCT } \\
\text { Follow-up (median): } 5.4 \text { yrs (range 4.9-6.3) } \\
\text { Population description: Mixed gender aduts } \geq \\
18 \text { yrs with history of CHD } \\
\text { Risk of bias assessment overall: Moderate } \\
\text { Funding: Mixed (foundation/public) }\end{array}$ & $\begin{array}{l}\text { Model: Logistic regresssion } \\
\text { Variables: Age, gender and other variables; LDL-C } \\
\text { not included } \\
\text { CVD Outcomes: Death of any cause and MACE } \\
\text { Lp(a) assay: Isoform independence - NR/unclear; } \\
\text { frozen samples }\end{array}$ & $\begin{array}{l}\text { Lp(a) comparison type: Categorical } \\
\text { Comparisons included were: } L p(a) \leq 38.25 \text { units/I (ref) vs. 38.26-91 units/l, } \\
91.1-289.75 \text { units/l, } \geq 289.76 \text { units/l } \\
\text { No effect sizes reported, but all six logistic regression analyses reported } \\
\text { a positive association, though this was only reported as statistically } \\
\text { significant for three out of six comparisons (two simvastatin arm } \\
\text { analyses and one placebo treatment arm). } \\
\text { The authors concluded that } L p(a) \text { independently predicts major coronary } \\
\text { events as well as death in the secondary population. }\end{array}$ \\
\hline $\begin{array}{l}\text { AIM-HIGH [67] ( } n=3414) \\
\text { Study design: RCT } \\
\text { Follow-up: } 3 \text { yrs (at trial termination) } \\
\text { Population description: Mixed gender adults } \geq \\
45 \text { yrs with established CVD and dyslipidemia } \\
\text { Risk of bias assessment overall': Low } \\
\text { Funding: Mixed (induxstry/public) }\end{array}$ & $\begin{array}{l}\text { Model: Cox proportional hazards } \\
\text { Variables: Age, gender and other variables; LDL-C } \\
\text { not included } \\
\text { CVD Outcomes: Ischemic stroke or TIA } \\
\text { Lp(a) assay: Isoform independence - NR; NR if fresh } \\
\text { or frozen samples }\end{array}$ & $\begin{array}{l}\text { Lp(a) comparison type: Categorical } \\
\text { Four effect sizes reported, including two for ischemic stroke and two } \\
\text { for ischemic stroke or TIA. Comparisons were between lowest tertile } \\
\text { (reference) Lp(a) and moderate tertile or highest tertile (Lp(a) levels } \\
\text { not defined). All showed a statistically significant positive association } \\
\text { (same direction). The maximum effect size reported was HR 2.8, } \\
95 \% \text { Cl: } 1.25 \text { to } 6.26 \text { (lowest tertile vs. highest tertile) and the lowest } \\
\text { HR 2.3, } 95 \% \text { Cl: } 1.19 \text { to } 4.42 \text { (lowest tertile vs. highest tertile) }\end{array}$ \\
\hline
\end{tabular}

Ezhov 2014 [68] $(n=356)$

Study design: Prospective cohort study

Follow-up: $8.5 \pm 3.5$ yrs (range $0.9-15.0$ yrs)

Population description: Mixed gender adults $\geq$

18 yrs with stable CHD after sucessful CABG

Risk of bias assessment overall: Low

Funding: NR

Model: Cox proportional hazards

Variables: Age, gender and other variables; LDL-C not included

CVD Outcomes: First cardiovascular event (non-fatal MI cardiovascular death, coronary revascularization, or hospitalization for recurrent angina)

Lp(a) assay: Isoform independent; fresh samples

GENERATION [69] $(n=483)$

Study design: Prospective cohort study

Follow-up: 1.84 yrs

Population description: Males adults $\geq 18$ yrs admitted to hospital with the diagnosis of either stable angina, NSTACS or STEMI

Risk of bias assessment overall: Not enough

information

Funding: NR

Model: Cox proportional hazards

Variables: Age, gender and other variables; LDL-C not included

for rest-unstable angina

Lp(a) assay: Isoform independence - NR/unclear frozen samples

ischemic stroke and elevated baseline Lp(a) [middle/highest tertile]

Lp(a) comparison type: Categorical

Two effect sizes reported, both were statistically significant showing a positive association (same direction) between $\mathrm{Lp}(\mathrm{a})$ and non-fatal $\mathrm{M}$ or CD (<30 mg/dl (reference) vs. $\geq 30 \mathrm{mg} / \mathrm{dl}:$ HR $2.98,95 \% \mathrm{Cl}: 1.76$ to 5.03 ) and first ever major CVD event ( $<30 \mathrm{mg} / \mathrm{dl}$ (ref) $\mathrm{vs.} \geq 30 \mathrm{mg} / \mathrm{dl}$ : HR 3.47, $95 \%$ Cl: 2.48 to 4.85

These results show that $\mathrm{Lp}(\mathrm{a})$ concentration is independently

associated with three-fold increase in risk of major adverse

cardiovascular events within 15 years after CABG.

Lp(a) comparison type: Categorical

Four effect sizes reported for comparison of $<25 \mathrm{mg} / \mathrm{dl}$ (reference) vs. $\geq 25 \mathrm{mg} / \mathrm{dl}$.

Three were statistically significant showing a positive association (same direction): HR 3.31, $95 \% \mathrm{Cl}: 1.33$ to 8.22 (non-fatal Ml); HR 2.09, $95 \%$ Cl: 1.16 to 4.12 (rehosptialisation for angina); HR 2.42, $95 \%$ Cl: 1.52 to 3.84 (CD, non-fatal Ml, hospitalisation for unstable angina)

One was NS: HR 1.27, 95 \% Cl: 0.48 to 3.34 (death)

Authors concluded that high plasma levels of either CRP or Lp(a)

may be associated with the incidence of late events after successful coronary stenting, but a more protracted latent period may be needed in order to manifest clinically the unfavorable influence of an elevated $L p(a)$ on atherosclerotic plaque instability. The authors also noted that there was not a statndardised analytic method for Lp(a) level determination. 
Table 4 Summary of studies in secondary prevention (14 studies) (Continued)

HERS [70] $(n=2759)$

Study design: RCT

Follow-up: 4.1 yrs

Population description: White elderly $\geq 50$ yrs

postmenopausal females with CHD - placebo

group from RCT

Risk of bias assessment overall: Not enough

information

Funding: Industry

Ikenaga $2011[71](n=410)$

Study design: Prospective cohort study

Follow-up: 5 yrs

Population description: Japanese mixed gender adults $\geq 18$ yrs with $\mathrm{PCl}$ after $\mathrm{Ml}: \mathrm{Lp}(\mathrm{a}) \geq 40 \mathrm{mg} / \mathrm{d}$ Risk of bias assessment overall: Not enough information

Funding: No financial support

Konishi 2013 [45] $(n=330)$

Study design: Prospective cohort study

Follow-up (median): $4.7 \mathrm{yrs}$

Population description: Mixed gender Japenese

adults $\geq 18$ yrs undergoing $\mathrm{PCl}$ with achieved

lipid targets: $L p(a) \geq 30 \mathrm{mg} / \mathrm{dl}$

Risk of bias assessment overall: High

Funding: Public

Kwon 2015 [73] $(n=1494)$

Study design: Prospective cohort study

Follow-up (mean): 4.4 (SD 2.6) yrs

Population description: Mixed gender Korean

adults $\geq 18$ yrs with diabetes and a history of

symptomatic CAD including IHD, stable/unstable angina, and $\mathrm{Ml}$

Risk of bias assessment overalla: Moderate

Funding: Public

LIPID [13] $(n=3949)$

Study design: $\mathrm{RCT}$

Follow-up: 6 yrs and 8 yrs

Population description: Mixed gender White

adults $\geq 18$ yrs with history of CVD (Lp(a)

$13.9-44.1 \mathrm{mg} / \mathrm{dl}$ )
Model: Cox proportional hazards

Variables: Age, gender and other variables; includes LDL-C

CVD Outcomes: Unstable angina; primary CHD events including

non-fatal $\mathrm{Ml}$ and $\mathrm{CHD}$ death; $\mathrm{M}$

$L p(a)$ assay: Isoform independent; NR if fresh or frozen samples

Model: Cox proportional hazards

Variables: Age, gender and other variables; LDL-C not included

CVD Outcomes: MACE (cardiac death, $\mathrm{MI}$ and/or revascularisation for new lesions): revascularisation for new lesion

L $p$ (a) assay: Isoform independence - NR/unclear: NR if fresh or frozen samples

Model: Cox proportional hazards and multivariable analysis Variables: Age, gender and other variables; LDL-C not included CVD Outcomes: All-cause death and ACS

$L p(a)$ assay: Isoform independence - NR/unclear; NR if fresh o frozen samples

Model: Cox proportional regression analysis

Variables: Age, gender and other variables; LDL-C leven not

included (hyperlipidemia defined as LDL-C of at least

$130 \mathrm{mg} / \mathrm{dL}$ was included)

CVD Outcomes: MACE

$L p(a)$ assay: Isoform independent; NR if fresh or frozen samples

Model: Cox proportional hazards

Variables: Age, gender and other variables; LDL-C not included CVD Outcomes: Total CHD events (non-fatal MI, CHD death,

unstable angina, coronary revascularization)

Lp(a) assay: Isoform independent; frozen samples
L (a) comparison type: Categorical

15 effect sizes reported for 5 different sets of CVD events. Only 2/15

analyses were statistically significant showing a positive association

(same direction):

$1^{\text {st }}$ quartile (Lp(a) 0.0-7.0 mg/dl - reference) vs. $4^{\text {th }}$ quartile ( $L$ (a) 55.0-236 $\mathrm{mg} / \mathrm{dl}): H R$ 1.54, $95 \% \mathrm{Cl}: 1$ to 2.4 (primary CHD events, e.g non-fatal Ml) $1^{\text {st }}$ quartile (Lp(a) 0.0-7.0 mg/dl - reference) vs. $4^{\text {th }}$ quartile (Lp(a) 55.0-236 $\mathrm{mg} / \mathrm{dl}): \mathrm{HR} 1.61,95 \% \mathrm{Cl}: 1.1$ to 2.3 (CABG/PTCA)

Overall, the authors concluded that $L p(a)$ is an independent risk factor for recurrent CHD in postmenopausal women.

Lp(a) comparison type: Categorical

Two effect sizes reported and both statistically significant showing a positive association: $\leq 40 \mathrm{mg} / \mathrm{dl}$ (reference) vs. $>40 \mathrm{mg} / \mathrm{dl}$ : HR 1.64, $95 \%$ Cl: 131 to 2.06 (MACE)

$\leq 40 \mathrm{mg} / \mathrm{dl}$ (reference) vs. $>40 \mathrm{mg} / \mathrm{dl}$ : HR $1.61,95 \% \mathrm{Cl}: 1.32$ to 2.13

(revascularisation for new lesions)

Results show that $L p(a)$ levels can significantly and independently predict the progression of non-culprit lesions after acute MI

Lp(a) comparison type: Categorical

Two effect sizes reported and both statistically significant showing a positive association (same direction):

$\leq 30 \mathrm{mg} / \mathrm{dl}$ (reference) vs. $\geq 30 \mathrm{mg} / \mathrm{dl}:$ HR 1.68, $95 \%$ Cl: 1.03 to 2.7 (Cox proportional hazards)

$\leq 30 \mathrm{mg} / \mathrm{dl}$ (reference) vs. $\geq 30 \mathrm{mg} / \mathrm{dl}:$ HR $2.47,95 \%$ Cl: 1.19 to 5.06

(multivariable analysis)

Results showed that high $\mathrm{Lp}(\mathrm{a})[\mathrm{z} 3 \mathrm{mg} / \mathrm{dL}$ ] could independently predict major adverse events

Lp(a) comparison type: Categorical

Two effect sizes (adjusting for age, gender, hypertension, hyperlipidemia,

smoking and extent of (AD) reported and both statistically significant showing a positive association (same direction) with risk of MACE:

Tertile 1 (median $4.7 \mathrm{mg} / \mathrm{dL}$; reference) vs. Tertile 2 (median $13.5 \mathrm{mg} / \mathrm{dL}$ ): HR $1.54,95 \% \mathrm{Cl}: 0.68$ to 3.50

Tertile 1 (median $4.7 \mathrm{mg} / \mathrm{dL}$; reference) vs. Tertile 3 (median $38.8 \mathrm{mg} / \mathrm{dL}$ ): HR $2.89,95 \% \mathrm{Cl}: 1.37$ to 6.08

In addition, a survival probability plot according to $L p(a)$ tertile suggested that elevated $L p(a)$ level was associated with a worse prognosis $(p=0,008)$ after

adjusting for age, gender, hypertension, hyper lipidemia, smoking and extent of CAD

Results suggested elevated $\operatorname{Lp}(a)$ is associated with worse outcomes (MACE) in type 2 diabetics patients with symptomatic CAD and has incremental prognostic value.

L $p$ (a) comparison type: Categorical

36 effect sizes were reported across 3 different comparisons and 12 differen CVD outcomes. 11/39 effect sizes were statistically significant analyses (all positive association (same direction). Effect size ranges were:

From $\leq 13.9 \mathrm{mg} / \mathrm{dl}$ (reference) vs. $>73.7 \mathrm{mg} / \mathrm{dl}: \mathrm{HR} 1.21,95 \% \mathrm{Cl}: 1.07$ to 1.36 ) To $\leq 13.9 \mathrm{mg} / \mathrm{dl}$ (reference) vs. $>73.7 \mathrm{mg} / \mathrm{dl}:$ HR $1.45,95 \% \mathrm{Cl}: 1.2$ to 1.75 28/39 analyses were NS including 3 at 8 yr follow-up and 28 at 6 yr follow-up 
Table 4 Summary of studies in secondary prevention (14 studies) (Continued)

Risk of bias assessment overalla: Moderate

Funding: Industry

Park 2015 [72] $(n=161)$

Study design: Prospective cohort study (retrospective analysis of prospective

registry data)

Follow-up (median): 6 yrs (maximum: 8 yrs) Population description: Mixed gender adults $\geq$ 18 yrs undergoing PCl

Risk of bias assessment overall: Moderate Funding: NR

\section{RESEARCH [74] $(n=161)$}

Study design: Prospective cohort study

Follow-up (median): 6 yrs (maximum: 8 yrs)

Population description: Mixed gender adults $\geq$

18 yrs undergoing $P C$

Risk of bias assessment overall": Moderate

Funding: NR

Rosengren 1990 [75] ( $n=155)$

Study design: Nested case-control study

Follow-up: 6 yrs

Population description: Males $\geq 50$ yrs with

Ml or CHD death

Risk of bias assessment overall ${ }^{\text {: }}$ : Moderate

Funding: Mixed (foundation/ public)

TNT Study [76] $(n=1506)$

Study design: $\mathrm{RCT}$

Follow-up (median): 4.9 yrs

Population description:Mixed gender adults $\geq$

40 yrs who have experienced major

cardiovascular events and are receiving

statin treatment

Risk of bias assessment overall: High

Funding: Pharma
Model: Cox proportional hazards

Variables: Age, gender and other variables; LDL-C included CVD Outcomes: MACE

Lp(a) assay: Isoform independence - NR/unclear; NR if fresh or frozen samples

Model: Cox proportional hazards

Variables: Age gender and other variables; LDL-C not included CVD Outcomes: MACE

$L p(a)$ assay: Isoform independent; frozen samples

Model: Logistic regression

Variables: Age, gender and other variables; LDL-C not included CVD Outcomes: CHD deaths and non-fatal MI

$L p(a)$ assay: Isoform independence - NR/unclear; frozen samples

Model: Cox proportional hazards regression

Variables: Age, gender and other variables; LDL-C not included CVD Outcomes: CHD death; non-fatal, non-procedure-related myocardial infarction; resuscitated cardiac arrest; and fatal or nonfatal stroke.

Lp(a) assay: Commercial assay; Immunoturbidimetric assay; Isoform dependence - NR/unclear; NR if fresh or frozen samples
Overall, the authors concluded that baseline $L p(a)$ and increased $L p(a)$ concentrations after one year were independently associated with future cardiovascular disease and CHD events.

Lp(a) comparison type: Categorical

Cox proportional hazards regression analysis adjusted for gender, age, diabetes mellitus, hypertension, hyperlipidemia, smoking, multivessel disease, minimal luminal diameter after PCl, reference vessel diameter after PCI, LDL-C, total lesion length, $L p(a) \geq 50 \mathrm{mg} / \mathrm{dL}$, showed that $L p(a)>50 \mathrm{mg} / \mathrm{dL}$ (vs. $L p(a) \leq$ $50 \mathrm{mg} / \mathrm{dL}$ ) was significantly associated with the $3 \mathrm{yr}$ adverse clinical outcomes including any MI, revascularization (target lesion revascularization (TLR) and target vessel revascularization (TVR)), TLR- MACEs, TVR-MACE, and All-MACEs. One significant effect size: OR 2.88, $95 \%$ Cl: 1.37 to 6.07 .

Authors concluded that high $\mathrm{Lp}(\mathrm{a})$ level $\geq 50 \mathrm{mg} / \mathrm{dL}$ in angina pectoris

patients undergoing elective PCI with DES was significantly associated with

binary restenosis and $3 \mathrm{yr}$ adverse clinical outcomes in an Asian population.

Lp(a) comparison type: Categorical

Eight effect sizes reported. Five out of eight effect sizes were statistically

significant and all were positive association (same direction). These ranged from:

Lp(a) tertile 1 (cut point $0.27 \mathrm{mg} / \mathrm{dl}$ - reference) vs. Lp(a) tertile 3 (> $1.83 \mathrm{mg} / \mathrm{dl}):$ HR $1.9,95 \% \mathrm{Cl}: 1$ to 3.5

To Lp(a) tertile 1 (cut point $0.27 \mathrm{mg} / \mathrm{dl}$ - reference) vs. Lp(a) tertile 2

(cutpoint $1.83 \mathrm{mg} / \mathrm{dl}:$ HR 3.7, $95 \%$ Cl: 1.4 to 10.1

Three out of eight analyses were NS

The results showed that high levels of $L p(a)$ were independently associated with a higher 1-year risk of MACE,

Lp(a) comparison type: Categorical

One effect size reported for the comparison of controls (reference) vs.

cases. This was reported as statistically significant difference for the association (same direction)

The results show that serum $L p(a)$ concentration is an independen risk factor for subsequent $\mathrm{Ml}$ or death from $\mathrm{CHD}$

Lp(a) comparison type: Categorical

Three effect sizes reported. Two out of three effect sizes were statistically significant and all were positive association (same direction).

One effect size was reported in whole population for $\operatorname{Lp}(a)$ with major CV events: HR 1.17, $95 \%$ Cl: 1.04 to 1.33. Other significant effect size was reported in subgroup atorvastatin $10 \mathrm{mg}$ QD for $\mathrm{Lp}(\mathrm{a})$ with major CV

events: HR 1.34, $95 \% 1.12$ to 1.6

No significant effect in Atorvastatin $80 \mathrm{mg}$ subgroup $1.01(95 \% \mathrm{Cl}$ 0.85 to 1.20$)$

Results suggest that higher plasma levels of $L p(a)$ are independently associated with an increased risk of recurrent events. 
Table 4 Summary of studies in secondary prevention (14 studies) (Continued)

Wehinger 1999 [77] $(n=2223)$

Study design: Prospective cohort study

Follow-up: 1 yr

Population description: Mixed gender adults $\geq$

18 yrs successfully treated with intracoronary

stent due to symptomatic CAD

Risk of bias assessment overall: Moderate

Funding: NR
Variables: Age, gender and other variables; LDL-C not included

CVD Outcomes: Angiographic restenosis

Lp(a) assay: Isoform independence - NR/unclear; fresh samples
L (a) comparison type: Categorica

Four effect sizes reported. All were NS for the comparison between

$L p(a)$ quintiles (2 to 3 ) vs. $L p(a)$ quintile 1.

Results suggest that elevated $L p(a)$ levels did not influence the one-year

clinical and angiographic outcome after stent placement. Thrombotic events and measures of restenosis were not adversely affected by the presence of high $L p(a)$ levels.

a Overall risk of bias as assessed by QUIPS tool [24]

4S Scandinavian Simvastatin Survival Study; ACS acute coronary syndrome; AIM-HIGH Atherothrombosis Intervention in Metabolic Syndrome with low HDL/High Triglycerides: Impact on Global Health Outcomes; CABC coronary artery bypass grafting; CAD coronary artery disease; CHD coronary heart disease; Cl confidence interval; CVD cardiovascular disease; dl decilitre; GENERATION Global Evaluation of New Events and Restenosis After Stent Implantation; HDL high-density lipoprotein; HERS Heart and Estrogen/progestin Replacement Study; HR hazard ratio; LDL-C low-density lipoprotein; I litre; LIPID Long-Term Intervention with Pravastatin in Ischaemic Disease; Lp(a) lipoprotein a; max maximum; MACE major coronary events; mg milligram; MI myocardial infarction; min minimum; NR not reported; NSTACS non-ST-segment elevation acute coronary syndrome; PCl percutaneous coronary intervention; PTCA percutaneous transluminal coronary angioplasty; QUIPS Quality In Prognosis Studies; RCT; ref reference; RESEARCH Rapamycin-Eluting Stent Evaluated At Rotterdam Cardiology Hospital; STEMI ST-segment elevation acute myocardial infarction; TG triglyceride; TIA transient ischemic attack; yrs years 
hyperlipidemia (defined as LDL-C $\geq 130 \mathrm{mg} / \mathrm{dL}$ ) as a variable in the multivariable model. This study also concluded that elevated $\mathrm{Lp}(\mathrm{a})$ is associated with worse outcomes (MACE) in type 2 diabetics patients with symptomatic CAD (Tertile 1 [median $4.7 \mathrm{mg} / \mathrm{dL}$; reference] versus Tertile 2 [median $13.5 \mathrm{mg} / \mathrm{dL}$ ]: HR 1.54, $95 \%$ CI: 0.68 to 3.50 and Tertile 1 [median $4.7 \mathrm{mg} / \mathrm{dL}$; reference] versus Tertile 3 [median $38.8 \mathrm{mg} / \mathrm{dL}$ ]: HR 2.89, $95 \%$ CI: 1.37 to 6.08$)$.

Five studies (HERS; [70] Ezhov 2014; [68] LIPID; [13] Kwon 2015; [73] and RESEARCH [74]) reported the use of an isoform independent $\mathrm{Lp}(\mathrm{a})$ assay. All of these studies concluded that increased baseline $[13,68,70,72]$ or follow-up [13] $\mathrm{Lp}$ (a) concentration was a significant and independent risk factor for CVD events including recurrent CHD [70], MACE [68, 73], total CHD events [13] and prognosis after PCI [74]. HERS [70] reported that increased baseline $\mathrm{Lp}(\mathrm{a})$ concentrations $(\geq 25.4 \mathrm{mg} / \mathrm{dL})$ of $\mathrm{Lp}(\mathrm{a})$ were associated with significant and independent increased in CHD (HRs between 1.01 and 1.31). Ezhov 2014 [68] reported that stable CHD patients with $\mathrm{Lp}(\mathrm{a}) \geq 30 \mathrm{mg} / \mathrm{dL}$ were at a significantly greater risk of cardiovascular death and MI (HR 2.98, 95 \% confidence interval [CI]: 1.76 to 5.03 ) and cardiovascular death, MI, hospitalization for recurrent or unstable angina and repeat revascularization (HR 3.47, 95 \% CI: 2.48 to 4.85), than patients with $\mathrm{Lp}(\mathrm{a})$ values $<30 \mathrm{mg} / \mathrm{dL}$. The LIPID [13] study as reported that increased baseline Lp(a) concentrations were independently associated with an increased risk of total CHD events $(p<0.001)$, total cardiovascular disease events $(p=0.002)$, and coronary events $(p=0.03)$. The authors also reported that the greatest risk occurred at $\mathrm{Lp}(\mathrm{a})$ concentrations $>73 \mathrm{mg} / \mathrm{dL}$ (upper decile) and that an increase in $\mathrm{Lp}(\mathrm{a})$ concentration at 1 year was associated with an increased risk of total CHD events and total cardiovascular disease events (both $p=0.002$ ). The RESEARCH [74] study concluded that there was a significant and independent association between $\mathrm{Lp}(\mathrm{a})$ concentrations before $\mathrm{PCI}$ and a higher risk of MACE at 1-year follow-up (HR 3.1, 95 \% CI: 1.1 to 8.6 for the highest versus $[\geq 65.2 \mathrm{nmol} / \mathrm{L}]$ the lowest tertile $[<9.8 \mathrm{nmol} / \mathrm{L}])$. However, the authors reported that this association weakened and lost significance with long-term follow-up.

Overall, half of the studies included Lp(a) level as a continuous variable and the other half of the studies used categorical data. Where $\mathrm{Lp}(\mathrm{a})$ was assessed as a categorical value, the thresholds for the categories differed between studies. Across all of the 14 studies, 91 effect sizes were reported for the association between $\mathrm{Lp}(\mathrm{a})$ and CVD events, 36 were statistically significant, showing a positive association, between increased $L p(a)$ levels and the risk of CVD events (HRs ranged from 0.75 to 3.7). Only one study reported a negative association
(Wehringer 1999 [77]), which was not statistically significant. This study concluded that elevated Lp(a) mass did not influence the one-year clinical and angiographic outcome after stent placement [77].

The remaining 53 analyses suggested that $\mathrm{Lp}(\mathrm{a})$ predicted CV outcomes (HRs ranged from 1.21 to 3.7), though not all of the effect sizes were statistically significant. This included results from five studies (4S study; [66] GENERATION; [69] HERS; [70] LIPID; [13, 74] and RESEARCH [74]). Although some non-significant results for subgroup and sensitivity analyses were reported in these five studies, all concluded that high Lp(a) concentrations (range $\geq 25$ to $65.2 \mathrm{mg} / \mathrm{dL}$ ) were significant predictors of CVD events, including in populations of postmenopausal women with CHD [70], patients with previous CHD [66], stable CHD [13], stable and unstable coronary syndromes after coronary stenting [69] and short term progress after PCI [74].

\section{Discussion}

This review presents contemporary evidence examining the extent of relationship between Lp(a) levels and CVD outcomes. The strengths of the review include the adherence to validated rigorous systematic review methodology. This is also one of the first systematic reviews to examine high risk primary prevention patients and secondary prevention populations separately, while only focusing on evidence from multivariable analyses which took into consideration potential confounders.

Our review suggests that evidence is available to support an independent positive association between $\mathrm{Lp}(\mathrm{a})$ and the risk of future CVD events both in the general population and in high risk populations, such as those with diabetes, hypertension, or on dialysis. Evidence also exists to support the positive independent association of $\mathrm{Lp}(\mathrm{a})$ mass with CVD events in secondary prevention populations. The number of studies for high risk primary prevention populations and secondary prevention populations was limited.

Our findings confirm previous reviews of primary prevention studies; $[16,18]$ including a review by the Emerging Risk Factors Collaboration published in 2009. This review of 37 prospective studies $(n=1,40,956)$ reported that $\mathrm{Lp}(\mathrm{a})$ modelled as continuous and categorical variables, was an independent risk factor for coronary heart disease death, nonfatal MI, and stroke [16]. The review used individual patient data from the included studies and focused on the primary prevention of coronary heart disease, stroke and non-vascular mortality. In comparison, our review was based on study level data and included a much broader range of CVD outcomes and encompasses primary prevention in high risk population and secondary prevention populations.

Our review found four out of 57 studies which concluded that $\mathrm{Lp}$ (a) mass was not a predictor of subsequent 
events. This included three primary prevention studies $[33,39,51]$ in the general population and one in a high risk population [58]. The study in a high risk population reported that in stable haemodialysis patients measuring outcomes at two years, Lp(a) mass was related to the development of overall death and cardiovascular death, but suggested that it was involved in an acute phase reaction and successful treatment of the inflammatory condition may improve long-term survival and so explain the lack of an association with mortality in these patients [58]. The primary prevention studies in the general population concluded that there was no overall statistically significant association between $\mathrm{Lp}(\mathrm{a})$ mass and the risk of all-cause mortality, cumulative fatal-nonfatal stroke, and cumulative fatal-nonfatal CAD events [51], ischemic stroke in postmenopausal women [39] and peripheral arterial disease in men [33]. This may have been due to inadequate measurement methods for $\mathrm{Lp}(\mathrm{a})$ in comparison with other primary prevention studies, although methods were not always clearly described with respect to their isoform independence [39].

With respect to the relationship between $L p(a)$ mass and the secondary prevention of CVD outcomes, our review found some evidence to support a positive association in agreement with previous reviews in this population $[81,82]$ including a recent review by O'Donoghue [20]. Unlike our review, O'Donoghue and colleagues had access to individual patient data from three studies (PEACE Prevention of Events with Angiotensin Converting Enzyme Inhibition; [83] CARE - Cholesterol and Recurrent Event); [84] and PROVE IT-TIMI 22 Pravastatin or Atorvastatin Evaluation and Infection Therapy-Thrombolysis In Myocardial Infarction 22 [85] trials) and were able to pool these data. When combined with in some cases unpublished data from eight previous studies (FATS - Familial Atherosclerosis Treatment Study; [86] 4S; [66] HERS; [70] GENERATION; [69] Saely 2006; [87] Skinner 1997; [88] Stubbs 1998; [89] and AIM-HIGH [67]) the authors also found a significant association between $\mathrm{Lp}(\mathrm{a})$ and the risk of future myocardial infarction, MACE (OR 1.40, 95 \% CI: 1.15 to 1.71). This suggests that although our review did not necessarily have access to all of these trial data, similar conclusions were evident.

Only one study [77] in our review concluded that elevated $\mathrm{Lp}(\mathrm{a})$ levels were not predictive of CVD events after stent placement. In this case, $L p(a)$ mass was found not to influence the one-year clinical and angiographic outcome after stent placement, but the study did not use a standardised assay for $\mathrm{Lp}(\mathrm{a})$ level determination and may have been confounded by the use of antithrombotic drugs post stent placement [77]. Previous reviews in secondary prevention have similarly reported a positive association between $\mathrm{Lp}(\mathrm{a})$ and CVD event for populations including those who have experienced a stroke [81], and patients who have experienced in-stent restenosis after coronary stenting [82]. However, unlike our review these reviews have not focused specifically on multivariable studies to control for confounding factors.

The relationship between $L p(a)$ mass and stroke is of particular interest clinically and our review suggests that there is evidence to suggest a significant positive relationship between $\mathrm{Lp}(\mathrm{a})$ and non-haemorrhagic stroke in high risk [54,65] and secondary prevention [67] populations, in agreement with the findings of other recent reviews [16]. However, the risk relationship in the general population was not as clearly defined, with the suggestion that an effect is only present in certain subgroups of the population. For instance, $\mathrm{Lp}(\mathrm{a})$ appeared to independently predict fatal and non-fatal stroke/TIA in middle-aged men [26], but not for ischemic stroke in postmenopausal women [39]. The effects of $L p(a)$ levels on stroke including ischemic stroke were not as well investigated however, and there is a need for more well designed studies to look at the specific effects of $\mathrm{Lp}(\mathrm{a})$ with regard to the different stroke subtypes including ischemic stroke.

The identification of $\mathrm{Lp}(\mathrm{a})$ as a potential risk factor for $\mathrm{CVD} / \mathrm{CHD}$ risk prompts the question as to whether this would be an appropriate biomarker for risk stratification and screening [90]. To date, RCTs have not been performed in patients with elevated $\mathrm{Lp}$ (a) levels that were randomized to a therapy, primarily due to lack of therapeutic agents developed specifically to lower $\mathrm{Lp}(\mathrm{a})$. In addition, there is also a lack of clinical trial evidence to show that $\mathrm{Lp}(\mathrm{a})$ reduction (independent of effects on LDL-C) lowers CVD event risk. Only half of the studies in our review included LDL-C as a variable in the multivariable model. Despite this, some studies have suggested a genetic basis for a link between $\mathrm{Lp}(\mathrm{a})$ and CVD. Evidence from multiple genome wide association [91, 92] and Mendelian randomization studies [93], suggested that LPA gene variants (encoding $\mathrm{Lp}(\mathrm{a})$ lipoprotein) were strongly associated with both an increased level of $\mathrm{Lp}(\mathrm{a})$ lipoprotein and an increased risk of coronary disease. However, a more recent Mendelian randomization study has suggested that $\mathrm{Lp}(\mathrm{a})$ promotes CVD through atherosclerotic stenosis whereas possible prothrombotic effects appear less influential [94]. In addition, evidence suggests that $\mathrm{Lp}(\mathrm{a})$-lowering therapy such as a $\mathrm{Lp}(\mathrm{a})$ apheresis with immunabsorption against human apo(a) results in a significant improvement in the stenosis of the coronary arteries without evidence of other major changes in the lipid profile [95].

In addition, $\mathrm{Lp}$ (a) may enhance risk discrimination and reclassification; a recent study on the predictive role of $\mathrm{Lp}(\mathrm{a})$ in long-term (15 years) CVD outcomes in general community showed that the net reclassification improvement afforded by $\mathrm{Lp}(\mathrm{a})$ was as high as $39.6 \%$ in intermediate-risk group and indicated that $\mathrm{Lp}(\mathrm{a})$ can 
modify clinical risk assessment [96, 97]. The $2015 \mathrm{Na}$ tional Lipid Association recommendations for patientcentered management of dyslipidemia suggest that the presence of $\mathrm{Lp}(\mathrm{a})$ levels of $50 \mathrm{mg} / \mathrm{dL}$ or more may warrant moving a patient into a higher risk category [98]. Similarly, the European Atherosclerosis Society consensus panel recommends screening for elevated $\mathrm{Lp}(\mathrm{a})$ in those at intermediate or high CVD/CHD risk and a desirable level $<50 \mathrm{mg} / \mathrm{dL}$ as a function of global cardiovascular risk [18]. This would also suggest that current and future treatments which reduce Lp(a) levels, such as apheresis $[95,99]$, antisense therapy which targets Apo(a) [100] and PCSK9 inhibitors [10, 101, 102] could provide additional benefit in the treatment of patients at risk of CVD beyond LDL-C lowering [18], and evidence of such additional benefit beyond LDL-C lowering should be investigated further in ongoing and future trials [103].

The analysis within our review was limited by the inability to carry out statistical pooling/meta-analysis. This was not possible due to the considerable variation in outcomes, modelling and $\mathrm{Lp}(\mathrm{a})$ assays used. Little can also be concluded about the concurrent effects of LDL-C and $\mathrm{Lp}(\mathrm{a})$ as very few of the included studies considered both LDL-C and Lp(a) as model variables. Poor reporting of study methodology in some of the studies also hampered the conduct of the review, particularly during the study selection process and the risk of bias assessment. In addition, in some cases relevant data for studies were not available from individual study publications and were only available in pooled analyses from groups of trialists, which were not eligible for inclusion in our review.

Issues with $\mathrm{Lp}(\mathrm{a})$ measurement were also problematic and hampered interpretation as has been noted by previous review authors $[11,104]$. The methods used to measure $\mathrm{Lp}(\mathrm{a})$ mass were also poorly reported. At present research suggests that there are no commercially available assays that are completely and truly insensitive to the variability in $L p(a)$ particle mass, and so the development of assays which are mass-insensitive are key to the future interpretation of $\mathrm{Lp}(\mathrm{a})$ risk prediction studies [104]. However, for the purposes of this review we have used the authors' description to classify whether studies were isoform dependent or independent. In the majority of cases the classification was either not reported or unclear. However, the authors of one study (Cho 2010 [46]) clearly reported that the test used was isoform dependent and 17 studies that the test used was isoform independent (CCHS; [97] Chin-Shan Community Cardiovascular Cohort Study; [42] CHOICE; [53] CHS; [105] D’Angelo 2006; [106] EPIC; [107] Ezhov 2014; [68] FHS; [108] GRIPS; [28] HERS; [70] HPFS; [32] LIPID; [13] Lipid Research Clinics Coronary Primary Prevention trial; [35] NHS; [109] RESEARCH; [74] Saely 2006; [87] and WHS [40]). No obvious differences between these two sets of studies were evident in terms of the significance and direction of effects for the relationship. All of the studies of high risk prevention and secondary prevention population that reported the use of an isoform independent test concluded that $\mathrm{Lp}$ (a) was an independent risk factor for CVD events. Future studies should ensure that their methodology, including $\mathrm{Lp}$ (a) assay methods is clearly reported, given the potential issues relating to the reliability of $L p(a)$ measurement and comparability between assays.

\section{Conclusions}

There is evidence to suggest that increased $L p(a)$ levels are associated with modest increases in the risk of future CVD in both of the lower and higher risk populations reviewed. Therapies that provide $\operatorname{Lp}(\mathrm{a})$ lowering in addition to LDL-C lowering such as PCSK9 inhibitors and antisense therapy which targets Apo(a), should be investigated for additional benefit in these populations beyond the expected benefits of the LDL-C lowering.

\section{Additional files}

Additional file 1: Search strategies. (DOCX $25 \mathrm{~kb}$ )

Additional file 2: Table S1. Summary of study characteristics (60 studies). (DOCX 59 kb)

Additional file 3: Table S2. Summary of QUIPS quality assessment domains (60 studies). (DOCX 54 kb)

\section{Abbreviations}

4S: Scandinavian Simvastatin Survival Study; ACS: acute coronary syndrome; AIM-HIGH: Atherothrombosis Intervention in Metabolic Syndrome with low HDL/High Triglycerides: Impact on Global Health Outcomes;

Apo(a): apoprotein(a); ASCVD: atherosclerotic cardiovascular disease; CABG: coronary artery bypass grafting; CAD: coronary artery disease; CD: coronary death; CV: cardiovascular; CHD: coronary heart disease; CHOICE: Choices for Healthy Outcomes in Caring for ESRD; Cl: confidence interval; CVD: cardiovascular disease; dl: decilitre; ECG: electrocardiogram; ESRD: end stage renal disease; GENERATION: Global Evaluation of New Events and Restenosis After Stent Implantation; HDL: high-density lipoprotein; HERS: Heart and Estrogen/progestin Replacement Study; HF: heart failure; HR: hazard ratio; ICD: International Classification of Diseases; IHD: ischemic heart disease; JDS: Japan Diabetes Complications Study; LDL-C: low density lipoprotein cholesterol; I: litre; LIPID: Long-Term Intervention with Pravastatin in Ischaemic Disease; Lp(a): lipoprotein(a); max: maximum; LVH: left ventricular hypertrophy; MACE: major adverse cardiac events; mg: milligram; Ml: myocardial infarction; min: minimum; mth: months; NR: not reported; NS: not significant; NSTACS: non-ST-segment elevation acute coronary syndrome; OR: odds ratio; PAD: peripheral arterial disease; PCI: percutaneous coronary intervention; PTCA: percutaneous transluminal coronary angioplasty; QUIPS: Quality In Prognosis Studies; $\mathrm{RCT}$ : randomised controlled trial; RESEARCH: Rapamycin-Eluting Stent Evaluated At Rotterdam Cardiology Hospital; STEMI: ST-segment elevation acute myocardial infarction; TIA: transient ischemic attack; TG: triglyceride; TLR: target lesion revascularization; TVR: target vessel revascularization; UK: United Kingdom; USA: United States of America; WHO: World Health Organisation; Yrs: years.

\section{Competing interests}

RQ, SG and SD are Amgen Inc. employees and stockholders. NW serves as a Amgen Inc. consultant/advisory board participant. CF, SD, GW, RW, JK and LS are employees of Kleijnen Systematic Reviews (KSR) Ltd., an independent research company who have been paid by Amgen Inc. to carry out this work. 


\section{Authors' contributions}

CF - concept and design; data inclusion assessment; data extraction and quality assessment; data analysis and interpretation; manuscript draft and final approval. RGWQ - concept and design data review and interpretation; drafting and final approval of the manuscript. GW - concept and design; data inclusion assessment; data extraction and quality assessment; data analysis and interpretation; drafting and final approval of the manuscript. SD - concept and design; data inclusion assessment; data extraction and quality assessment; data analysis and interpretation; drafting and final approval of the manuscript. RW - concept and design; data analysis and interpretation; drafting and final approval of the manuscript. LS - literature searching, drafting and final approval of the manuscript. JK - concept and design; data analysis and interpretation; drafting and final approval of the manuscript. SRG - concept and design data review and interpretation; drafting and final approval of the manuscript. SD - concept and design; data analysis and interpretation; drafting and final approval of the manuscript. NW - data review and interpretation; drafting and final approval of the manuscript.

\section{Acknowledgements}

The authors acknowledge the help of the following reviewers who assisted with data extraction and quality assessment: Debra Fayter, Shona Lang, Kim Reid and Adrian Hernandez. In addition, Janine Ross, an Information Specialist assisted in the development of the search strategies.

\section{Source of Funding}

This study was funded by Amgen Inc. (Thousand Oaks, California, USA).

\section{Author details}

'Kleijnen Systematic Reviews Ltd, Unit 6, Escrick Business Park, Riccall Road, Escrick, York YO19 6FD, UK. ${ }^{2}$ Amgen Inc, One Amgen Center Drive, Thousand Oaks, CA 91320-1799, USA. ${ }^{3}$ School for Public Health and Primary Care, Maastricht University, Maastricht, The Netherlands. ${ }^{4}$ University of California, Heart Disease Prevention Program, C240 Medical Sciences, University of California, Mail Code: 4079, Irvine, CA 92697, USA.

\section{Received: 15 March 2016 Accepted: 2 May 2016 Published online: 17 May 2016}

\section{References}

1. Moran AE, Tzong KY, Forouzanfar MH, Rothy GA, Mensah GA, Ezzati M, et al. Variations in ischemic heart disease burden by age, country, and income: the Global Burden of Diseases, Injuries, and Risk Factors 2010 study. Glob Heart. 2014;9(1):91-9.

2. World Health Organization. Cardiovascular diseases (CVDs) [Internet]: World Health Organization, 2015 [accessed 23.9.15] Available from: http://www. who.int/mediacentre/factsheets/fs317/en/. Accessed 9 May 2016.

3. Cholesterol Treatment Trialists Collaboration. Efficacy and safety of more intensive lowering of LDL cholesterol: a meta-analysis of data from 170000 participants in 26 randomised trials. Lancet. 2010;376(9753):1670-81.

4. Baigent C, Keech A, Kearney PM, Blackwell L, Buck G, Pollicino C, et al. Efficacy and safety of cholesterol-lowering treatment: prospective meta-analysis of data from 90,056 participants in 14 randomised trials of statins. Lancet. 2005; 366(9493):1267-78

5. Cannon CP, Blazing MA, Giugliano RP, McCagg A, White JA, Theroux P, et al. Ezetimibe added to statin therapy after acute coronary syndromes. N Engl J Med. 2015;372(25):2387-97.

6. European Medicines Agency. CPMP note for guidance on clinical investigation of medicinal products in the treatment of lipid disorders (CPMP/EWP/3020/2003). London: EMEA; 2004.

7. European Medicines Agency. CPMP draft guidelines on note for guidance on clinical investigation of medicinal products in the treatment of lipid disorders(EMA/CPMP/3020/2003). London: EMEA; 2010.

8. Nicholls SJ, Tang WH, Scoffone H, Brennan DM, Hartiala J, Allayee H, et al. Lipoprotein(a) levels and long-term cardiovascular risk in the contemporary era of statin therapy. J Lipid Res. 2010;51(10):3055-61.

9. Siekmeier R, Scharnagl H, Kostner GM, Grammer T, Stojakovic T, März W. Lipoprotein(a) - Structure, Epidemiology, Function and Diagnostics of a Cardiovascular Risk Marker. Open Clin Chem J. 2008;1:79-91.

10. Spence JD, Koschinsky M. Mechanisms of lipoprotein(a) pathogenicity: prothrombotic, proatherosclerotic, or both? Arterioscler Thromb Vasc Biol. 2012;32(7):1550-1.
11. Guadagno PA, Summers Bellin EG, Harris WS, Dayspring TD, Hoefner DM, Thiselton DL, et al. Validation of a lipoprotein(a) particle concentration assay by quantitative lipoprotein immunofixation electrophoresis. Clin Chim Acta. 2015:439:219-24.

12. Schmitz G, Orso E. Lipoprotein(a) hyperlipidemia as cardiovascular risk factor: pathophysiological aspects. Clin Res Cardiol Suppl. 2015;10:21-5.

13. Nestel PJ, Barnes EH, Tonkin AM, Simes J, Fournier M, White HD, et al. Plasma lipoprotein(a) concentration predicts future coronary and cardiovascular events in patients with stable coronary heart disease. Arterioscler Thromb Vasc Biol. 2013;33(12):2902-8.

14. Khera AV, Everett BM, Caulfield MP, Hantash FM, Wohlgemuth J, Ridker PM, et al. Lipoprotein(a) concentrations, rosuvastatin therapy, and residual vascular risk: an analysis from the JUPITER Trial (Justification for the Use of Statins in Prevention: an Intervention Trial Evaluating Rosuvastatin). Circulation. 2014;129(6):635-42.

15. Albers JJ, Slee A, O'Brien KD, Robinson JG, Kashyap ML, Kwiterovich Jr PO, et al. Relationship of apolipoproteins A-1 and B, and lipoprotein(a) to cardiovascular outcomes: the AIM-HIGH trial (Atherothrombosis Intervention in Metabolic Syndrome with Low HDL/High Triglyceride and Impact on Global Health Outcomes). J Am Coll Cardiol. 2013;62(17):1575-9.

16. Collaboration ERF, Erqou S, Kaptoge S, Perry PL, Di Angelantonio E, Thompson A, et al. Lipoprotein(a) concentration and the risk of coronary heart disease, stroke, and nonvascular mortality. JAMA. 2009;302(4):412-23.

17. Danesh J, Collins R, Peto R. Lipoprotein(a) and coronary heart disease. Meta-analysis of prospective studies. Circulation. 2000;102(10):1082-5.

18. Nordestgaard BG, Chapman MJ, Ray K, Borén J, Andreotti F, Watts GF, et al. Lipoprotein(a) as a cardiovascular risk factor: current status. Eur Heart J. 2010;31(23):2844-53.

19. Craig WY, Neveux LM, Palomaki GE, Cleveland MM, Haddow JE. Lipoprotein(a) as a risk factor for ischemic heart disease: metaanalysis of prospective studies. Clin Chem. 1998;44(11):2301-6.

20. O'Donoghue ML, Morrow DA, Tsimikas S, Sloan S, Ren AF, Hoffman EB, et al. Lipoprotein(a) for risk assessment in patients with established coronary artery disease. J Am Coll Cardiol. 2014;63(6):520-7.

21. Bennet A, Di Angelantonio E, Ergou S, Eiriksdottir G, Sigurdsson G, Woodward $\mathrm{M}$, et al. Lipoprotein(a) levels and risk of future coronary heart disease: large-scale prospective data. Arch Intern Med. 2008;168(6):598-608.

22. Higgins JPT, Green S, eds. Cochrane handbook for systematic reviews of interventions [Internet]. Version 5.1.0 [updated March 2011]: The Cochrane Collaboration, 2011 [accessed 23.3.11]. Available from: http://handbook. cochrane.org/

23. Centre for Reviews and Dissemination. Systematic Reviews: CRD's guidance for undertaking reviews in health care [Internet]. York: University of York; 2009. [accessed 23.3.11] Available from: http://www.york.ac.uk/inst/crd/ SysRev/ISSL!/WebHelp/SysRev3.htm. Accessed 9 May 2016.

24. Hayden JA, van der Windt DA, Cartwright JL, Côté P, Bombardier C. Assessing bias in studies of prognostic factors. Ann Intern Med. 2013;158(4):280-6.

25. PRISMA Group. PRISMA (Preferred Reporting Items for Systematic Reviews and Meta-Analyses) statement [Internet]. [accessed 18.6.15]. Available from: http://prisma-statement.org/. Accessed 9 May 2016.

26. Wiberg B, Sundstrom J, Arnlov J, Terent A, Vessby B, Zethelius B, et al. Metabolic risk factors for stroke and transient ischemic attacks in middle-aged men: a community-based study with long-term follow-up. Stroke. 2006:37(12):2898-903.

27. Watt HC, Law MR, Wald NJ, Craig WY, Ledue TB, Haddow JE. Serum triglyceride: a possible risk factor for ruptured abdominal aortic aneurysm. Int J Epidemiol. 1998;27(6):949-52.

28. Cremer P, Nagel D, Labrot B, Mann H, Muche R, Elster H, et al. Lipoprotein $\mathrm{Lp}(\mathrm{a})$ as predictor of myocardial infarction in comparison to fibrinogen, $\mathrm{LDL}$ cholesterol and other risk factors: results from the prospective Gottingen Risk Incidence and Prevalence Study (GRIPS). Eur J Clin Invest. 1994;24(7):444-53.

29. Thogersen AM, Soderberg S, Jansson JH, Dahlen G, Boman K, Nilsson TK, et al. Interactions between fibrinolysis, lipoproteins and leptin related to a first myocardial infarction. Eur J Cardiovasc Prev Rehabil. 2004;11(1):33-40.

30. Seed M, Ayres KL, Humphries SE, Miller GJ. Lipoprotein (a) as a predictor of myocardial infarction in middle-aged men. Am J Med. 2001;110(1):22-7.

31. Jauhiainen M, Koskinen P, Ehnholm C, Frick MH, Manttari M, Manninen V, et al. Lipoprotein (a) and coronary heart disease risk: a nested case-control study of the Helsinki Heart Study participants. Atherosclerosis. 1991;89(1):59-67.

32. Pischon T, Girman CJ, Sacks FM, Rifai N, Stampfer MJ, Rimm EB. Non-highdensity lipoprotein cholesterol and apolipoprotein B in the prediction of coronary heart disease in men. Circulation. 2005;112(22):3375-83. 
33. Ridker PM, Stampfer MJ, Rifai N. Novel risk factors for systemic atherosclerosis: a comparison of C-reactive protein, fibrinogen, homocysteine, lipoprotein(a), and standard cholesterol screening as predictors of peripheral arterial disease. JAMA. 2001;285(19):2481-5.

34. Luc G, Bard JM, Arveiler D, Ferrieres J, Evans A, Amouyel P, et al. Lipoprotein (a) as a predictor of coronary heart disease: the PRIME Study. Atherosclerosis. 2002;163(2):377-84.

35. Schaefer EJ, Lamon-Fava S, Jenner JL, McNamara JR, Ordovas JM, Davis CE, et al. Lipoprotein(a) levels and risk of coronary heart disease in men. The Lipid Research Clinics Coronary Primary Prevention Trial. JAMA. 1994;271(13): 999-1003.

36. Sweetnam PM, Bolton CH, Downs LG, Durrington PN, Mackness MI, Elwood PC, et al. Apolipoproteins A-I, A-II and B, lipoprotein(a) and the risk of ischaemic heart disease: the Caerphilly study. Eur J Clin Invest. 2000;30(11):947-56.

37. Assmann G, Schulte H, von Eckardstein A. Hypertriglyceridemia and elevated lipoprotein(a) are risk factors for major coronary events in middle-aged men. Am J Cardiol. 1996;77(14):1179-84.

38. Cantin B, Gagnon F, Moorjani S, Despres JP, Lamarche B, Lupien PJ, et al. Is lipoprotein(a) an independent risk factor for ischemic heart disease in men? The Quebec Cardiovascular Study. J Am Coll Cardiol. 1998;31(3):519-25.

39. Berger JS, McGinn AP, Howard BV, Kuller L, Manson JE, Otvos J, et al. Lipid and lipoprotein biomarkers and the risk of ischemic stroke in postmenopausal women. Stroke. 2012;43(4):958-66.

40. Pradhan AD, Shrivastava S, Cook NR, Rifai N, Creager MA, Ridker PM. Symptomatic peripheral arterial disease in women: nontraditional biomarkers of elevated risk. Circulation. 2008;117(6):823-31.

41. Kim BJ, Kim BS, Sung KC, Kang JH, Lee SH, Lee JY. Relationship between lipoprotein(a) level and mortality in 72766 Korean adults. Eur Heart J. 2015:36:358-9

42. Chien KL, Hsu HC, Su TC, Sung FC, Chen MF, Lee YT. Lipoprotein(a) and cardiovascular disease in ethnic Chinese: the Chin-Shan Community Cardiovascular Cohort Study. Clin Chem. 2008;54(2):285-91.

43. Wang W, Hu D, Lee ET, Fabsitz RR, Welty TK, Robbins DC, et al. Lipoprotein(a) in American Indians is low and not independently associated with cardiovascular disease. The Strong Heart Study. Ann Epidemiol. 2002;12(2):107-14.

44. Uchiyama S, Nakaya N, Mizuno K, Ohashi Y, Tajima N, Kushiro T, et al. Risk factors for stroke and lipid-lowering effect of pravastatin on the risk of stroke in Japanese patients with hypercholesterolemia: analysis of data from the MEGA Study, a large randomized controlled trial. J Neurol Sci. 2009;284(1-2):72-6.

45. Konishi H, Miyauchi K, Naito R, Tsuboi S, Ogita M, Kasai T, et al. Impact of lipoprotein (A) as residual risk on long-term outcomes in patients underwent PCl. Circulation. 2013;128(22 Suppl 1):A12805.

46. Cho JY, Jeong MH, Ahn Y, Hong YJ, Park HW, Yoon NS, et al. High lipoprotein(a) levels are associated with long-term adverse outcomes in acute myocardial infarction patients in high Killip classes. Korean Circ J. 2010;40(10):491-8.

47. Ohira T, Schreiner PJ, Morrisett JD, Chambless LE, Rosamond WD, Folsom AR. Lipoprotein(a) and incident ischemic stroke: the Atherosclerosis Risk in Communities (ARIC) study. Stroke. 2006;37(6):1407-12.

48. Volpato S, Vigna GB, McDermott MM, Cavalieri M, Maraldi C, Lauretani F, et al. Lipoprotein(a), inflammation, and peripheral arterial disease in a community-based sample of older men and women (the InCHIANTI study). Am J Cardiol. 2010;105(12):1825-30

49. Virani SS, Brautbar A, Davis BC, Nambi V, Hoogeveen RC, Sharrett AR, et al. Associations between lipoprotein(a) levels and cardiovascular outcomes in black and white subjects: the Atherosclerosis Risk in Communities (ARIC) Study. Circulation. 2012;125(2):241-9.

50. Rifai N, Ma J, Sacks FM, Ridker PM, Hernandez WJ, Stampfer MJ, et al. Apolipoprotein(a) size and lipoprotein(a) concentration and future risk of angina pectoris with evidence of severe coronary atherosclerosis in men: the Physicians' Health Study. Clin Chem. 2004:50(8):1364-71.

51. Solfrizzi V, Colacicco AM, D'Introno A, Capurso C, Chirico M, Frisardi V, et al. All-cause mortality and competing risks of fatal and nonfatal vascular events in the Italian longitudinal study on aging: impact of lipoprotein(a). Rejuvenation Res. 2009;12(6):395-402.

52. Agewall S, Fagerberg B. Lipoprotein(a) was an independent predictor for major coronary events in treated hypertensive men. Clin Cardiol. 2002;25(6):287-90.

53. Longenecker JC, Klag MJ, Marcovina SM, Liu YM, Jaar BG, Powe NR, et al. High lipoprotein(a) levels and small apolipoprotein(a) size prospectively predict cardiovascular events in dialysis patients. J Am Soc Nephrol. 2005;16(6):1794-802
54. Cressman MD, Heyka RJ, Paganini EP, O'Neil J, Skibinski Cl, Hoff HF. Lipoprotein(a) is an independent risk factor for cardiovascular disease in hemodialysis patients. Circulation. 1992;86(2):475-82.

55. Pernod G, Bosson JL, Golshayan D, Barro C, Forneris G, Martina G, et al. Phenotypic and genotypic risk factors for cardiovascular events in an incident dialysis cohort. Kidney Int. 2006;69(8):1424-30.

56. Sone H, Tanaka S, limuro S, Tanaka S, Oida K, Yamasaki Y, et al. Long-term lifestyle intervention lowers the incidence of stroke in Japanese patients with type 2 diabetes: a nationwide multicentre randomised controlled trial (the Japan Diabetes Complications Study). Diabetologia. 2010;53(3):419-28.

57. Koda Y, Nishi S, Suzuki M, Hirasawa Y. Lipoprotein(a) is a predictor for cardiovascular mortality of hemodialysis patients. Kidney Int Suppl. 1999;71:S251-3.

58. Zimmermann J, Herrlinger S, Pruy A, Metzger T, Wanner C. Inflammation enhances cardiovascular risk and mortality in hemodialysis patients. Kidney Int. 1999;55(2):648-58

59. Schreiner PJ, Wu KK, Malinow MR, Stinson VL, Szklo M, Nieto FJ, et al. Hyperhomocyst(e)inemia and hemostatic factors: the atherosclerosis risk in communities study. Ann Epidemiol. 2002;12(4):228-36.

60. Kwon SW, Yoon YW, Lee BK, Kim J-Y, Choi E-Y, Hong B-K, et al. Elevated lipoprotein(a) is associated with worse outcome in type 2 diabetic patients with symptomatic coronary artery disease. J Am Coll Cardiol. 2014;63(12):A1539.

61. Morishita R, Sakaki M, Yamamoto K, Iguchi S, Aoki M, Yamasaki K, et al. Impairment of collateral formation in lipoprotein(a) transgenic mice: therapeutic angiogenesis induced by human hepatocyte growth factor gene. Circulation. 2002;105(12):1491-6.

62. Czupryniak L, Strzelczyk J, Pawlowski M, Loba J. Mild elevation of fasting plasma glucose is a strong risk factor for postoperative complications in gastric bypass patients. Obes Surg. 2004;14(10):1393-7.

63. Goldwasser P, Avram MM, Collier JT, Michel MA, Gusik SA, Mittman N. Correlates of vascular access occlusion in hemodialysis. Am J Kidney Dis. 1994;24(5):785-94.

64. Shishkina VS, Toklueva LR, Kashirina SV, Radiukhina NV, Il'inskaia OP, Akhmetov W, et al. Comparison of morphological features of carotid arteries atherosclerotic plaques with clinical-instrumental data in symptomatic and asymptomatic patients with severe carotid atherosclerosis. Kardiologiia. 2013;53(4):25-31.

65. Chambless LE, Shahar E, Sharrett AR, Heiss G, Wijnberg L, Paton CC, et al. Association of transient ischemic attack/stroke symptoms assessed by standardized questionnaire and algorithm with cerebrovascular risk factors and carotid artery wall thickness. The ARIC Study, 1987-1989. Am J Epidemiol. 1996;144(9):857-66.

66. Berg K, Dahlen G, Christophersen B, Cook T, Kjekshus J, Pedersen T. Lp(a) lipoprotein level predicts survival and major coronary events in the Scandinavian Simvastatin Survival Study. Clin Genet. 1997;52(5):254-61.

67. Teo KK, Goldstein LB, Chaitman BR, Grant S, Weintraub WS, Anderson DC, et al. Extended-release niacin therapy and risk of ischemic stroke in patients with cardiovascular disease: the Atherothrombosis Intervention in Metabolic Syndrome with low HDL/High Triglycerides: Impact on Global Health Outcome (AIM-HIGH) trial. Stroke. 2013;44(10):2688-93.

68. Ezhov MV, Safarova MS, Afanasieva OI, Kukharchuk W, Pokrovsky SN. Lipoprotein(a) level and apolipoprotein(a) phenotype as predictors of long-term cardiovascular outcomes after coronary artery bypass grafting. Atherosclerosis. 2015;235(2):477-82.

69. Zairis MN, Ambrose JA, Manousakis SJ, Stefanidis AS, Papadaki OA, Bilianou $\mathrm{HI}$, et al. The impact of plasma levels of $\mathrm{C}$-reactive protein, lipoprotein (a) and homocysteine on the long-term prognosis after successful coronary stenting: the global evaluation of new events and restenosis after stent implantation study. J Am Coll Cardiol. 2002;40(8):1375-82.

70. Shlipak MG, Simon JA, Vittinghoff E, Lin F, Barrett-Connor E, Knopp RH, et al. Estrogen and progestin, lipoprotein(a), and the risk of recurrent coronary heart disease events after menopause. JAMA. 2000;283(14):1845-52.

71. Ikenaga $\mathrm{H}$, Ishihara M, Inoue I, Kawagoe T, Shimatani Y, Miura F, et al. Usefulness of Lipoprotein (a) for predicting progression of non-culprit coronary lesions after acute myocardial infarction. Circ J. 2011;75(12):2847-52.

72. Park SH, Rha SW, Choi BG, Park JY, Jeon U, Seo HS, et al. Impact of high lipoprotein(a) levels on in-stent restenosis and long-term clinical outcomes of angina pectoris patients undergoing percutaneous coronary intervention with drug-eluting stents in Asian population. Clin Exp Pharmacol Physiol. 2015;42(6):588-95

73. Kwon SW, Kim JY, Sung JM, Yoon YW, Rhee JH, Lee BK, et al. Elevated Lipoprotein(a) has Incremental Prognostic Value in Type 2 Diabetic Patients 
with Symptomatic Coronary Artery Disease. J Atheroscler Thromb. 2015; 22(5):527-34.

74. Kardys I, Oemrawsingh RM, Kay IP, Jones GT, McCormick SP, Daemen J, et al. Lipoprotein(a), interleukin-10, C-reactive protein, and 8-year outcome after percutaneous coronary intervention. Clin Cardiol. 2012;35(8):482-9.

75. Rosengren A, Wilhelmsen L, Eriksson E, Risberg B, Wedel H. Lipoprotein (a) and coronary heart disease: a prospective case-control study in a general population sample of middle aged men. BMJ. 1990;301 (6763):1248-51

76. Arsenault BJ, Barter P, DeMicco DA, Bao W, Preston GM, LaRosa JC, et al. Prediction of cardiovascular events in statin-treated stable coronary patients of the treating to new targets randomized controlled trial by lipid and non-lipid biomarkers. PLoS ONE [Electronic Resource]. 2014;9(12):e1 14519.

77. Wehinger A, Kastrati A, Elezi S, Baum H, Braun S, Neumann FJ, et al. Lipoprotein(a) and coronary thrombosis and restenosis after stent placement. J Am Coll Cardiol. 1999;33(4):1005-12.

78. Graham I, Cooney MT, Bradley D, Dudina A, Reiner Z. Dyslipidemias in the prevention of cardiovascular disease: risks and causality. Curr Cardiol Rep. 2012;14(6):709-20.

79. Stubbs P, Seed M, Moseley D, O'Connor B, Collinson P, Noble M. A prospective study of the role of lipoprotein(a) in the pathogenesis of unstable angina. Eur Heart J. 1997:18(4):603-7.

80. Levitsky LL, Scanu AM, Gould SH. Lipoprotein(a) levels in black and white children and adolescents with IDDM. Diabetes Care. 1991;14(4):283-7.

81. Smolders B, Lemmens R, Thijs V. Lipoprotein (a) and stroke: a meta-analysis of observational studies. Stroke. 2007;38(6):1959-66.

82. Qin SY, Liu J, Jiang HX, Hu BL, Zhou Y, Olkkonen VM. Association between baseline lipoprotein (a) levels and restenosis after coronary stenting: meta-analysis of 9 cohort studies. Atherosclerosis. 2013;227(2):360-6.

83. Braunwald E, Domanski MJ, Fowler SE, Geller NL, Gersh BJ, Hsia J, et al. Angiotensin-converting-enzyme inhibition in stable coronary artery disease. N Engl J Med. 2004;351(20):2058-68.

84. Sacks FM, Pfeffer MA, Moye LA, Rouleau JL, Rutherford JD, Cole TG, et al. The effect of pravastatin on coronary events after myocardial infarction in patients with average cholesterol levels. Cholesterol and Recurrent Events Trial investigators. N Engl J Med. 1996;335(14):1001-9.

85. Cannon CP, Braunwald E, McCabe CH, Rader DJ, Rouleau JL, Belder R, et al. Intensive versus moderate lipid lowering with statins after acute coronary syndromes. N Engl J Med. 2004;350(15):1495-50.

86. Brown G, Albers JJ, Fisher LD, Schaefer SM, Lin JT, Kaplan C, et al. Regression of coronary artery disease as a result of intensive lipid-lowering therapy in men with high levels of apolipoprotein B. N Engl J Med. 1990;323(19):1289-98.

87. Saely CH, Koch L, Schmid F, Marte T, Aczel S, Langer P, et al. Lipoprotein(a), type 2 diabetes and vascular risk in coronary patients. Eur J Clin Invest. 2006;36(2):91-7.

88. Skinner JS, Farrer M, Albers CJ, Piper K, Neil HA, Adams PC. Serum Lp(a) lipoprotein concentration is not associated with clinical and angiographic outcome five years after coronary artery bypass graft surgery. Heart. 1997;78(2):131-5.

89. Stubbs P, Seed M, Lane D, Collinson P, Kendall F, Noble M. Lipoprotein(a) as a risk predictor for cardiac mortality in patients with acute coronary syndromes. Eur Heart J. 1998;19(9):1355-64.

90. Jacobson TA. Lipoprotein(a), cardiovascular disease, and contemporary management. Mayo Clin Proc. 2013;88(11):1294-311.

91. Thanassoulis G, Campbell CY, Owens DS, Smith JG, Smith AV, Peloso GM, et al. Genetic associations with valvular calcification and aortic stenosis. N Engl J Med. 2013;368(6):503-12.

92. The CARDloGRAMplusC4D Consortium. Large-scale association analysis identifies new risk loci for coronary artery disease. Nat Genet. 2013;45(1):25-33.

93. Kamstrup PR, Tybjaerg-Hansen A, Steffensen R, Nordestgaard BG. Genetically elevated lipoprotein(a) and increased risk of myocardial infarction. JAMA. 2009;301(22):2331-9.

94. Kamstrup PR, Tybjærg-Hansen A, Nordestgaard BG. Genetic evidence that lipoprotein(a) associates with atherosclerotic stenosis rather than venous thrombosis. Arterioscler Thromb Vasc Biol. 2012;32(7):1732-41.

95. Safarova MS, Ezhov MV, Afanasieva Ol, Matchin YG, Atanesyan RV, Adamova IY, et al. Effect of specific lipoprotein(a) apheresis on coronary atherosclerosis regression assessed by quantitative coronary angiography. Atheroscler Suppl. 2013;14(1):93-9.

96. Willeit P, Kiechl S, Kronenberg F, Witztum JL, Santer P, Mayr M, et al. Discrimination and net reclassification of cardiovascular risk with lipoprotein(a): prospective 15-year outcomes in the Bruneck Study. J Am Coll Cardiol. 2014;64(9):851-60.
97. Kamstrup PR, Tybjærg-Hansen A, Nordestgaard BG. Extreme lipoprotein(a) levels and improved cardiovascular risk prediction. J Am Coll Cardiol. 2013;61(11):1146-56

98. Jacobson TA, Ito MK, Maki KC, Orringer $\mathrm{CE}$, Bays $\mathrm{HE}$, Jones $\mathrm{PH}$, et al. National lipid association recommendations for patient-centered management of dyslipidemia: part 1-full report. J Clin Lipidol. 2015;9(2):129-69.

99. Leebmann J, Roeseler E, Julius U, Heigl F, Spitthoever R, Heutling D, et al. Lipoprotein apheresis in patients with maximally tolerated lipid-lowering therapy, lipoprotein(a)-hyperlipoproteinemia, and progressive cardiovascular disease: prospective observational multicenter study. Circulation. 2013:128(24):2567-76.

100. Tsimikas S, Viney NJ, Hughes SG, Singleton W, Graham MJ, Baker BF, et al. Antisense therapy targeting apolipoprotein(a): a randomised, double-blind, placebo-controlled phase 1 study. Lancet. 2015;386(10002):1472-83.

101. Sabatine MS, Giugliano RP, Wiviott SD, Raal FJ, Blom DJ, Robinson J, et al. Efficacy and safety of evolocumab in reducing lipids and cardiovascular events. N Engl J Med. 2015;372(16):1500-9.

102. Raal F, Giugliano RP, Sabatine MS, Koren MJ, Blom D, Honarpour N, et al. Long-term reduction in lipoprotein (A) with the PCSK9 monoclonal antibody evolocumab (AMG 145): a pooled analysis of 3278 patients in phase 2, 3, and open label extension studies. Circulation. 2014;130.

103. Kronenberg F. Lipoprotein(a): there's life in the old dog yet. Circulation. 2014;129(6):619-21.

104. McConnell JP, Guadagno PA, Dayspring TD, Hoefner DM, Thiselton DL, Warnick GR, et al. Lipoprotein(a) mass: a massively misunderstood metric. J Clin Lipidol. 2014;8(6):550-3.

105. Ariyo AA, Thach C, Tracy R. Lp(a) lipoprotein, vascular disease, and mortality in the elderly. N Engl J Med. 2003;349(22):2108-15.

106. D'Angelo A, Ruotolo G, Garancini P, Sampietro F, Mazzola G, Calori G. Lipoprotein(a), fibrinogen and vascular mortality in an elderly northern Italian population. Haematologica. 2006;91(12):1613-20.

107. Gurdasani D, Sjouke B, Tsimikas S, Hovingh GK, Luben RN, Wainwright NW, et al. Lipoprotein(a) and risk of coronary, cerebrovascular, and peripheral artery disease: the EPIC-Norfolk prospective population study. Arterioscler Thromb Vasc Biol. 2012;32(12):3058-65.

108. Lamon-Fava S, Marcovina SM, Albers JJ, Kennedy H, Deluca C, White CC, et al. Lipoprotein(a) levels, apo(a) isoform size, and coronary heart disease risk in the Framingham Offspring Study. J Lipid Res. 2011;52(6):1181-7.

109. Shai I, Schulze MB, Manson JE, Stampfer MJ, Rifai N, Hu FB. A prospective study of lipoprotein(a) and risk of coronary heart disease among women with type 2 diabetes. Diabetologia. 2005;48(8):1469-76.

\section{Submit your next manuscript to BioMed Central and we will help you at every step:}

- We accept pre-submission inquiries

- Our selector tool helps you to find the most relevant journal

- We provide round the clock customer support

- Convenient online submission

- Thorough peer review

- Inclusion in PubMed and all major indexing services

- Maximum visibility for your research

Submit your manuscript at www.biomedcentral.com/submit
Biomed Central 